\title{
WestVirginiaUniversity
}

THE RESEARCH REPOSITORY @ WVU

Graduate Theses, Dissertations, and Problem Reports

2006

\section{Adolescent religiosity and conformity to parents: Is sex a moderator?}

\author{
Rebecca Kim Summers \\ West Virginia University
}

Follow this and additional works at: https://researchrepository.wvu.edu/etd

\section{Recommended Citation}

Summers, Rebecca Kim, "Adolescent religiosity and conformity to parents: Is sex a moderator?" (2006). Graduate Theses, Dissertations, and Problem Reports. 4273.

https://researchrepository.wvu.edu/etd/4273

This Thesis is protected by copyright and/or related rights. It has been brought to you by the The Research Repository @ WVU with permission from the rights-holder(s). You are free to use this Thesis in any way that is permitted by the copyright and related rights legislation that applies to your use. For other uses you must obtain permission from the rights-holder(s) directly, unless additional rights are indicated by a Creative Commons license in the record and/ or on the work itself. This Thesis has been accepted for inclusion in WVU Graduate Theses, Dissertations, and Problem Reports collection by an authorized administrator of The Research Repository @ WVU. For more information, please contact researchrepository@mail.wvu.edu. 


\title{
ADOLESCENT RELIGIOSITY AND CONFORMITY TO PARENTS: IS SEX A MODERATOR?
}

\author{
By \\ Rebecca Kim Summers \\ A THESIS \\ Submitted to \\ The Davis College of Agriculture, Forestry, and Consumer Sciences \\ at West Virginia University \\ in partial fulfillment of the requirements for the degree of \\ Master of Science \\ In \\ Family and Consumer Sciences \\ Department of Family and Consumer Sciences \\ Morgantown, West Virginia \\ 2006 \\ Committee Chair: Erron Huey, Ph.D. \\ Carol Markstrom, Ph.D. \\ John Jacob, Ph.D.
}

Keywords: adolescence, conformity to parents, religiosity 


\section{Abstract ADOLESCENT RELIGIOSITY AND CONFORMITY TO PARENTS: IS SEX A MODERATOR? \\ Rebecca Kim Summers}

This study examines relations between adolescent reports of conformity to their parents and religiosity and if these are moderated by the sex of the adolescent and parent. Self-report data was collected from 121 ninth and tenth graders enrolled in three nonmetropolitan high schools. Religiosity was measured by Schumm et. al.’s (1991) modified version of Gorsuch and Venable's (1983) scales. Conformity to Parents was assessed using Peterson's (Peterson, Rollins, \& Thomas, 1985) Conformity to Parents scales. Four regressions were used. Results indicate that females: a) report higher levels of conformity to parents and religiosity than males and b) that when adolescent they report higher levels of conformity to mothers, they also report higher levels of intrinsic religiosity. One unexpected finding was that females who reported higher levels of conformity to fathers also reported higher levels of intrinsic religiosity. Findings and implication are discussed. 
Table of Contents

Abstract

Table of Contents

iii

List of Figures

iv

List of Tables

Chapter I

Introduction

Chapter II

Review of Literature

Symbolic Interaction Theory

Adolescent Conformity

Religion and Adolescence

Intrinsic \& Extrinsic Religiosity

Adolescent Sex as a Moderator

Review of Literature Summary

Hypotheses

Chapter III

Methodology

Sample

Procedures

23

Measurements

23

Conformity to Parents

23

Religiosity

Chapter IV

Results

Chapter V

Discussion

Limitations

Practical Implications

43

Recommendation for Future Research

46

References

50

Appendices

59

Vitae 


\section{List of Figures}

Figure 1 -

Sex X Conformity to Mothers Interaction on Intrinsic Religiosity

Figure 2 -

Sex X Conformity to Fathers Interaction on Intrinsic Religiosity

\section{List of Tables}

Table 1 -

Sub-sample ANOVA's Comparing Family Form Differences on Each Variable

Table 2 -

Sub-sample Tukey HSD Comparing Family Form Differences on Conformity to 30 Mothers and Fathers

Table 3 -

Demographics for Sample and Proposed Sub-Sample

Table 4 -

Correlations and Variable Descriptives $(\mathrm{N}=127)$

Table 5 -

Adolescent Intrinsic and Extrinsic Regression Models ( $\mathrm{N}=127)$

Table 6 -

Slope Significance Tests for Intrinsic Religiosity 


\section{Chapter One}

Introduction

Developmental expressions of religion in the lives of youth extend from formal church attendance and ritual involvement to religious beliefs and knowledge, selfidentity, and participation in youth groups (King, Elder, \& Whitbeck, 1997). One of the most positive associations with religious development is engagement in prosocial behaviors. Children in religious communities are more successful in avoiding problem behavior than other youth, and they are more accomplished on prosocial behavior as well (King, et. al, 1997). Given that most religions have teachings that emphasize care and compassion for others, religiosity is a potential positive influence on adolescent prosocial behavior (Hardy \& Carlo, 2005). Furrow, King and White (2003) concluded that religious identity is linked with personal meaning and prosocial concern. Their study illustrated that religion provided a resource for meaning and purpose and a sense of commitment to caring for others beyond themselves.

An important finding in research is the unique relationships between identity, religion, and prosocial commitments. Religious traditions, beliefs and values are embedded within social relations that seek to embody and model ideologies, histories, and traditions that in turn can sustain a young person with a sense of identity, purpose, and belonging (Erikson, 1959). Furrow et al (2003) found that for many, caring values, attitudes, and behaviors were not independent of their spirituality; rather, all aspects of the morality were governed by their religious beliefs and experience, which informed their goals of service and care and which were closely related to their identity. Thus, an adolescent's religious development is a crucial influence on their social development. However, the ways in which parent-child relationships may shape religious development 
also received only sporadic consideration by social scientist throughout the last century (Jenkins, 1992).

Alternately, adolescent conformity to their parent is an important aspect of cooperative relationships within families (Peterson, Rollins, \& Thomas, 1985). Durkheim (1961) supported this by stating that effective interpersonal interaction within families and other group relationships require that youth develop a moderate degree of interdependence or conformity to the expectations of important social agents. In this study, the focus is on adolescent conformity in relation to their internalized values. Research indicates that there are two dimensions of adolescent conformity, namely, internalization and external responsiveness (without internal commitment) (Peterson, et. al., 1985). Studies have shown that internalized conformity is more beneficial to the adolescent's development. Compared to situations in which obedience occurs in response to external surveillance, adolescent conformity based on personal commitment and choice (i.e., internalization) seems more consistent with the development of autonomy and individuality (Hogan, 1975; Kelman, 1958; Kiesler, 1969; Waterman, 1981).

In addition to adolescent conformity, the biological sex of the adolescent may also moderate the adolescent's religious development and conformity to parental beliefs. There is a wealth of evidence that indicates a number of significant psychological differences between males and females. According to Pomerantz, Fei-Yin Ng, and Wang (2004) parents are a central influence in children's psychological development and that parents play a major role in the development of these differences. Based on previous research, female adolescents report higher levels of conformity (Henry, Sager, \& Plunkett, 1989) and higher intrinsic religiosity (Flor \& Knapp, 2001). This may or may 
not be due to the fact that mothers are found to be more religious (Cornwall, 1989) and that mothers show higher levels of religious influence on their children (Hayes \& Pittlekow, 1993).

Based on these ideas, the current study's purpose is to examine adolescent conformity to mothers and fathers in relation to their religious development with a possible moderator effect of adolescent biological sex. This topic was chosen due to a lack of research focusing on adolescent conformity to parents, let alone, how religious affiliation and how the possibility of the adolescent's sex may influence this conformity. The general research question is do adolescents who report higher conformity to parental expectations also report higher intrinsic and extrinsic religiosity and if so, does the sex of the adolescent moderate the relation between adolescent reports of conformity to parents and their religiosity? 


\section{Chapter Two}

Review of the Literature

\section{Symbolic Interaction Theory}

According to Symbolic Interaction Theory, people act based on their perceptions and their perceptions are based on their interactions. As the name suggests, "symbolic interactionism" focuses on the connection between symbols (i.e., shared meanings) and interactions (i.e., verbal and nonverbal actions and communications) (LaRossa \& Reitzes, 1993). Turner (1978) characterized the core of symbolic interactionism as consisting in the assertions that: (a) humans create, use, and communicate with symbols; (b) they interact through role taking, which involves the reading of symbols used by others; (c) they are unique as a species through having a mind and self, which arise out of interaction, and (d) which allow for the interactions that form the basis of society. In addition, the symbolic interaction approach is concerned not only with externally observable or measurable circumstances, such as age, body appearance, social class, behavior, and values, but also with the symbolic meaning human beings attach to these concepts (Steinmetz, 1999). Stryker (1964) stated that individual personality is a "natural" development from the existing social unit and the state of communication within that unit, and an important element in this development consists in the expectations of other. This means that society and the individual are inextricable linked and mutually determined. In turn, relationships are formed based upon the objects within the situations and through interactions. Thus, symbolic interaction theories present a “contextual perspective” on adolescent development (Peterson, 1987). 
A key element of this is that culture and social processes come to influence individual's perceptions through interacting with others. This element is based on the classic work by Herbert Blumer (1969) concerning the formation of symbols. Blumer asserted that human beings act toward things on the basis of the meanings that the things have for them. These things include anything that the human being may note in his world, including ideas, behavioral patterns, and emotions (Denzin, 1985). In turn, the meaning of such things derives, or arises from the social interaction that one has with other entities. Additionally, these meanings are handled in and modified through, an interpretative process used by the person in dealing with the things he encounters (Blumer, 1969). In short, people construct and use symbols based upon their interactions. Part of this process of symbol formation is related to the internalization of information. Internalization is essentially an individual's appropriation of external information into the construction of symbols that guides future interactions (Stryker, 1981; Weigert, Teitge \& Teitge, 1986). Internalizing social information from interactions appears to follow a consistent path. The path progresses from identification of pertinent information and social models to accommodation of expected behaviors in social contexts and finally to incorporation of varied pieces of information forming symbols. This means that the standards and values held by significant others become more meaningful to the individual through the process of internalization (Rosenberg, 1981, Simmons, 1987; Stryker, 1964, 1980). However, the importance of this internalized information for adolescent development and behavior is related to the extent to which they choose to conform to the perceived others' standards and values (Peterson, 1987). 
Thus, conformity to others is the key issue relating internalized information to social behaviors.

In regards to religion, however, there is a challenge because religion can either provide meaning for a person's experiences or symbolize a way that a person should interact with others and their world (Regnerous, Smith, \& Fritsch, 2003). One reason for this is that religion can be an enhancing experience for youths because it provides answers for more complex issues of existence (Erickson, 1964, 1965). Another way to look at this is that the intrinsically motivated person "lives his religion" to the extent that he or she internalizes and follow personally adopted religious prescriptions (Allport \& Ross, 1967; p. 434), while an extrinsically motivated person uses his religion.

Furthermore, internal and external motivations are known to be significant indicators of adolescent conformity. Flor and Knapp (2001) found that clearly distinguishing between internal and external dimensions of religious behaviors clarifies the significant relations between adolescent values and behavior and those expressed by their parents.

Moreover, since parents and family are a child's primary social group, they can influence how the child perceives religion and religious behaviors through socialization. Socialization is the process by which we acquire the symbols, beliefs, and attitudes of our culture (Klein \& White, 1996). For example, research indicates that if parents hold religious behaviors in high regard, their adolescent children tend to learn to accept and value the importance of religion in their own lives. Studies of intergenerational transmission have found that the degree of religious emphasis in the home was the strongest predictor of religious attitudes in college students (Hunsberger \& Brown, 1984). In a study by King, Elder, and Whitbeck (1997) they support the previous statement by 
stating that the religious behavior of parents and the intensity of their commitment establishes the family's religious culture and provides models of religious involvement for children. Essentially, this indicates that some socialization has occurred since parents are a primary source of information and symbols (Flor \& Knapp, 2001). Yet, this does not necessitate that parent's religious beliefs influence the child's perceptions of their interactions or others, or motivate religious behaviors. Rather, it presents a question of how adolescent conformity to their parents relates to their religious development.

\section{Adolescent Conformity}

Adolescent conformity to their parents is an important process in developing a healthy sense of who they are and their relationships with others. Conformity is the regulation of behaviors to fit the perceived expectations and standards of others (Peterson, Rollins, \& Thomas, 1982). In turn, a moderate degree of interdependence, or conformity, between the expectations of important social agents encourages effective interpersonal interaction within families and other group relationships require that youth develop (Baumrind, 1978; Durkheim, 1961; Henry, Wilson, \& Peterson, 1989).

However, adolescence is a period characterized by ostensibly contradictory behaviors emphasizing a desire for individuality and autonomy alongside increased conformity (Duck \& Fortey, 2003, Peterson, 1995). Initiated by pubertal changes, adolescents actively revise and refine their symbols related to the self and social behaviors. In part, this is due to changes in feedback from others related to the adolescent's physical maturation (Peterson, 1987; Steinmetz, 1999). In turn, this leads to changes in social behaviors and perceptions of others and their values. Therefore, a large 
portion of adolescent development is related to the ability of adolescents to cope with the new social meanings assigned to the physical changes that they are experiencing.

In turn, adolescent conformity is influenced by two primary sources of social information, peers and parents. During adolescence, conformity to peers increases (Brown, Clausen, \& Eicher, 1986). As such, peers are routinely regarded as an influential component of an adolescent's interpersonal world and membership in a peer group is often seen as an essential part in maintaining a strong self-concept during the teenage years (Brown \& Lohr, 1987). However, parent-adolescent relationships are also influential in relation to peer-adolescent relationships and their development (Holmbeck, Paikoff, \& Brooks-Gunn, 1995; Steinmetz, 1999).

Further, research shows that conformity to parental beliefs produces positive outcomes in adolescents. Henry, Wilson, and Peterson (1989) found that parental support and physical affection was a positive predictor of adolescent conformity when used by the mother. Several authorities have argued that declining parental authority and insufficient conformity by the young are associated with high rates of deviance and are symptomatic of declines in the collective basis of society (Bronfenbrenner, 1970; Rollins \& Thomas, 1979). Research shows that in order to achieve positive adolescent conformity, parents must maintain a rational approach. Previous studies, for example, have found that adolescents whose parents use rational control attempts will be more compliant with parents and perceive them as desirable role models (Elder, 1963).

Conforming to parental beliefs would not be complete without discussing parental religious affiliation. In a study by King, Elder, and Whitbeck (1997), children who identified with their parents were more likely to be religious than youth who did not, but 
changes in this identification matter less. Naturally, adolescents who look at their parents as ideal role models will conceptually take into account their religious beliefs and what religion means to them. In addition, beliefs provide a means for generating behaviors, that may then affect the child's development, in response to parenting demands (McGillicuddy-Ke Lisi, Sigel, 1995). However, in one particular study by Gunnoe and Moore (2002), it was found that peer religiosity for youth aged 17-24 was highly influential.

Previous research also looks at which a parent has more influence on religious development. In a study by Francis and Gibson (1993) on parental influence and adolescent religiosity, using a sample of 3,414 adolescents aged 11-12 and 15-16, found that: (a) parental influence was important for both sexes and both age groups, (b) there was a little difference in overall parental influence on sons and daughters, and (c) the extent of the influence increased rather than decreased between the ages of 11 to 12 and 15 to 16 . The research also found that mothers' religious practice was a more powerful predictor than fathers' practice among both sons and daughters, that the comparative influence of the father was weaker among daughters than among sons, and that the comparative influence of the mother was stronger among daughters than among sons.

\section{Religion and Adolescence}

Research indicates that religion has a substantial presence in the lives of families all over the world. Ninety-five percent of married couples (Glenn, 1982) and parents (Mahoney, 2000) in the United States report having a religious affiliation. Furthermore, most parents are concerned with transmitting their religious values and beliefs to their 
children (Luft \& Sorell, 1987). In addition, a study by Heaton and Pratt (1990) indicated that many married American women and men attend church at least once a month $(60 \%$ and $53 \%$ respectively) and believe the Bible is the answer to all important human problems ( $49 \%$ and $42 \%)$, respectively. Although the figures may vary across cultures and across periods of the life course, at face value it appears that, "religion is an ever present and extremely important aspect of the historical, cultural, social and psychological realities that humans confront in their daily lives" (Hood, Spilka, Hunsberger, \& Gosuch, 1996).

Religion is a central dimension of human experience as youths and adults alike report high levels of religiosity (King \& Boyatzis, 2004). In the 1990's, one Gallup poll as cited by King and Boyatzis (2004) reported that some $75 \%$ of adolescents ages $13-17$ believed in a personal God and that $74 \%$ prayed at least occasionally. Concurrent to popular belief there is yet another dimension of personal belief. Batson (1976) and Batson and Ventis (1982) have suggested that we assess a "quest" dimension in addition to the highly popular extrinsic (means) and intrinsic (end) dimensions introduced by Allport (1959, 1966; Allport \& Ross 1967). According to Batson and Schoenrade (1991) religion as quest, they suggested, involves honestly facing existential questions in their complexity, while at the same time resisting clear-cut, pat answers. For example, an individual who approaches religion in this way recognizes that he or she does not know, and probably never will know, the final truth about such matters. There has been question on the validity of this measurement but it is something to consider and further investigation is needed. As part of the exploration associated with this transitory stage, adolescents begin to examine their religious identity and beliefs (Erikson, 1968). 
Parents typically teach their children religious beliefs, however, as the child enlarges upon what is taught, she or he develops an individual belief system under conditions of uncertainty (Ozarak, 1989). Further, according to King, Elder, and Whitbeck (1997) the religious behavior of parents and the intensity of the commitment establishes the family's religious culture and provides models of religious involvement for children. Moreover, the child's identification with parents, parental warmth, and emotional closeness enhances adolescent religiosity in relation to their conformity with parental practices.

Dudley (1993), found that those adolescents most committed to the church were less likely to have peers who used illegal drugs on a regular basis. Furthermore, they were not only less likely to use drugs but less likely to engage in intercourse or attempt suicide. Several studies provide support for religiousness as a buffer against risk behavior and a support for positive attitudes and actions among youth (Donahue \& Benson, 1995). Hardy and Carlo (2005) found that higher religiosity predicted higher anonymous prosocial behavior and that religiosity was significantly associated with higher altruistic prosocial behavior. Children in religious communities are more successful in avoiding problem behavior than other youth, and they are more accomplished on prosocial behavior as well (King et. al., 1997). An interesting study by Loury (2004) focusing on church attendance and schooling found that church attendance raised an important component of socioeconomic status in addition to its effects on health and subjective measure of well-being. They further concluded that church attendance significantly increased both the likelihood that individuals will complete high school and the likelihood they will attend college (Loury, 2004). 
Adolescents who are brought up with structure and belief systems will more than likely succeed and do well compared to adolescents that conform to peer pressure. King and Boyatzis (2004) supported this by stating that many youth turn toward religion and greater civic involvement, and yet many others who turn away from religion and join either gangs or hate groups, or become antisocial in other ways. As mentioned before, peer-conformity tends to be linked with negative anti-social behavior when compared to parental conformity. Roozen (1980) estimated that about $46 \%$ of Americans drop out of church participation at some time in their lives, with the peak occurring during the teenage years. Probable causes for the increase at this stage were lessening of parental influences as peer pressure and the emancipation process increased, plus the feeling that the church had little to offer that was relevant or interesting. Thus, adolescent's conformity to their parents may have a mitigating effect on the negative influence of peer-conformity.

From a symbolic interaction perspective, then, religious development would partially reflect the internalization of parental religious beliefs. Thus, developmental models for religious development should address aspects of the internalization process. Thus, religious development research should consider the potential influences of the parents as well as the more diverse influences of peers (Ozarak, 1989).

\section{Intrinsic \& Extrinsic Religiosity}

Allport and Ross (1967) first suggested that religious development can be categorized into intrinsic and extrinsic orientations as a way to distinguish positive from negative features of religiousness. They did this to clarify the confusing and seemingly 
contradictory research results regarding religiousness and prejudice (Allport \& Ross, 1967; Donahue, 1985).

Studies on the psychology of religion have employed a diverse spectrum of religious measures (Milevsky \& Levitt, 2004). Despite considerable controversy, instrinsic and extrinsic religious orientation remain in the forefront of the psychological study of religion (Genia, 1996). In the more traditional cultural transmission model, values are passed from the parent to the child uni-directionally and the child is seen as a passive recipient, accepting or not accepting the values transmitted by parents who are perceived as the active agents in the internalization process (Flor \& Knapp, 2001). Religiosity is defined as a commitment to, identification with, and involvement in a religion or system or religious beliefs (Hardy \& Carlo, 2005). Alternately, Gunnoe \& Moore (2002) define religiosity as the practice of being religious (e.g., attending religious services, praying, ascribing value to one's religious beliefs). For our purposes here, intrinsic religiosity refers to someone who lives his religion. This makes intrinsic religiosity a faith that comes from within the individual, or their spiritual drive that is motivated based on internalized values that are part of the individual (Paloutzian, 1996). Then on the other side of the Allport's dichotomy, extrinsic religiosity is when a person uses his religion. Therefore extrinsic religiosity indicates that religion is not internalized and is followed only for its perceived external benefit, such as social desirability and group membership (Paloutzian, 1996). Thus, a person motivated by extrinsic religiosity uses his religion as a means of obtaining status, security, self justification, and sociability, whereas the person motivated by intrinsic religiosity lives his religion regardless of the external consequences. 
Several studies provide support for the argument that intrinsic religiosity functions as a resource for positive psychological development among youth. Baker and Gorsuch (1982) indicated that intrinsicness appears to be associated with greater ego strength, more integrated social behavior, less paranoia or insecurity, and less anxiety. They also stated that intrinsicness is associated with the ability to integrate anxiety into everyday life in an adaptive manner. Wong-Mcdonald and Gorsuch (2004) found that a traditional conceptualization of God and intrinsic motivation were found to relate to great Spiritual Well-Being (SWB). Another study focusing on intrinsic religiosity, Markstrom and Smith (1996) found that while there is some evidence for the association of advance identity formation with intrinsic religiosity, a stronger conclusion can be made that intrinsics are not psychosocially immature. However, extrinsicness in this study was found to operate in an opposite manner, which indicated that it may be a more immature form of religiousness. A meta-analysis done by Donahue (1985) found that extrinsic religiousness tends to be positively correlated with negatively evaluated characteristics, and uncorrelated with measure of religious belief and commitment. He also found that intrinsic religiousness tends to be uncorrelated with negatively evaluated characteristics, and positively correlated with measure of religiousness. This is consistent with findings from Bergin, Masters, and Richards (1987) that extrinsic orientation reflects shallowness and a manipulative style that shows up in both religious and personality indexes.

On a psychological level, not only do intrinsically motivated people show positively related characteristics, but are more emotionally stable (Milevsky \& Levitt, 2004). A study assessing correlations between intrinsically motivated students and anxiety, found that students categorized as intrinsic reported lower anxiety levels and 
higher levels of self-control and "better" personality functioning (Bergin, Masters, \& Richards, 1987). In support to these findings, overall, Krause and Van Tran, (1987) found that religious individuals have been found to have less negative outcomes of stress.

These differences between intrinsic and extrinsic motivation appear to be based on personal commitment and choice (internalization) or external responsiveness (without internal commitment). That is, these differences seem to center on internalized conformity, or "society living within us" (Durkheim, 1961). Based on previous research, adolescents that have regular opportunities to engage in religious behaviors with their parents, such as attending church and praying are more likely to internalize these behaviors (Flor \& Knapp, 2001). These activities allow parents to model their own religious values and children to express their internalization of these values behaviorally (Flor \& Knapp, 2001). However, these behaviors may be merely external; compliance refers of conforming behavior that is demonstrated as a means of seeking rewards and avoiding punishments (Peterson et al., 1985). Thus, it is important to disentangle whether forms of adolescent religiosity are related to their conformity to their parents.

\section{Adolescent Sex as a Moderator}

Biological sex of the adolescent can either moderate, and possibly mediate, the effects of parental modeling and parent-child transactions on adolescent internalization (Flor \& Knapp, 2001). One possible explanation for this comes from the Hill and Lynch (1983) gender intensification hypothesis. This hypothesis is that during adolescence (especially early adolescence), sex-typed differences between boys and girls increase because of pressure to conform to traditional notions of masculinity and femininity. This 
leads to boys being socialized to be independent and assertive, while girls are socialized to be expressive and compliant. Therefore, adolescent conformity, or the internalized acceptance of these values, could influence the information contained in their internalized gender roles. Thus, shape their interactions with their parents and society.

While society plays a role in gender role development, children also acquire important information about gender roles based on the different kinds of social interaction with their mothers and fathers (McHale, Crouter, \& Whiteman, 2003). For example, in a study by Lanvers (2004) they found that by studying linguistic interaction, (a) mothers talked more to daughters than to sons, (b) mothers of daughters give more supportive speech, and (c) mothers used more marginally directive and linguistically restrictive styles to daughters than to sons. Alternately, fathers used more cognitively challenging language with sons than with daughters, who are generally less spoken to by their fathers, and gave more negative responses to daughters. Thus, boys are encouraged to display self-assertion, while girls are encouraged to display social compliance (Tenenbaum \& Leaper, 1998). Thus, there appears to be link between adolescent conformity their parents and the adolescent's sex.

These findings are consistent with the gender intensification hypothesis because these trends are evident in people's beliefs about the roles that females and males should fill within society (Pomerants, Fei-Yin Ng, \& Wang, 2004). In turn, these gender roles are instilled by parental influence and societal norms. Earlier research indicates that females are more prone to conform to parents and other social agents more extensively than males (Henry et al., 1989). Therefore, biological sex appears to be linked to the types and levels of conformity to parents and needs further examination. This is partially 
supported by a study done by Henry, Wilson, and Peterson (1989) where they noted that it was not exactly apparent why parental power predicted adolescent conformity, their results indicated that male and female adolescents varied in the extent to which they conformed to parents' expectations. Further, other research findings by Flor and Knapp (2001) indicated that adolescents' biological sex is related to their internalization of parental values and behavior in relation to religious behaviors.

Research indicates that there are gender differences between parents and their children, parents also play a role in their development of internalized information (Mchale, Crouter, \& Whiteman, 2003). An additional explanation for the apparent gender difference in religion is that there may exist differences in socialization between males and females that lead to religiosity differences as well (Milevsky \& Levitt, 2004). BeitHallahmi and Argyle (1997) proposed that, in nearly all cultures, females are socialized to be more nurturing, obedient, responsible, and active in religious work supporting and nurturing others. The large body of work that indicates parents are a central influence in children's psychological development suggests that parents play a major role in the development of these differences (Pomerantz, Fei Yin Ng, \& Wang, 2004). One area of focus of these differences is the way in which parents communicate with their children. Early research into gender differences reports invariably that mothers talk more than fathers to their children, and talks more to their daughters than sons (Cherry \& Lewis, 1976). Moreover, adolescent girls who experience relationships with a parent that involves open, frequent, communication may internalize more than adolescent girls who experience relationships with a parent who is less communicative and open (Flor \& 
Knapp, 2001). Differences between fathers and mothers in the style and amount of talk to children are by now well documented (Lanvers, 2004).

Additionally, sex of the adolescent also appears to be related to their religiosity. In multiple studies, males report higher levels of extrinsic religiosity while females report higher levels of intrinsic religiosity. Based on previous research, adolescent conformity to parents show that females tend to report higher intrinsic religiosity (Flor \& Knapp, 2001). Milevsky and Levitt (2004) also found in their study that females were found to score significantly higher on the intrinsic items than the males. These findings are consistent with a meta-analytic review by Donahue (1985), which concluded that there is evidence that females score higher on intrinsic scales than do males. One reason that Hardy and Carlo (2005) give for this sex difference is that, based on previous research, they also found that girls reported higher religiosity and altruistic prosocial behaviour and boys scored higher on public prosocial behaviour. Alternately, Flor and Knapp (2001) explained the sex differences as a result of the sex-typed activities encouraged by the parents, especially the fathers. They found, based on popular belief, that women across the lifespan are indeed more religious, and because of this, fathers perceived religiousness as a feminine characteristic and had less influence on the child's religious upbringing. Despite possible differences in explanations for why this occurs, each of these explanations are consistent with the gender intensification hypothesis because they support that there are gender prone characteristics of each parent and that each of them raise, mold, and form their sons and daughters differently from the beginning. Part of the differences between adolescent male and female religiosity, then, may influence the 
context of dyadic parent-child social exchanges. Thus, it appears that sex of the adolescent is linked to adolescent religiosity.

\section{Review of Literature Summary}

Research on the importance of adolescent conformity and religious development is quite abundant. It is evident that religious behavior is important in the lives of adolescents. As for adolescent conformity, it is broken down into only two influential groups, parents and peers. There is no profound research that states which is more so influential. The only findings are that parents tend to have a more positive influence than peers, especially when it comes to religious foundation. According to the research findings, adolescents that come from a religious upbringing are more likely to associate with others who are alike. Psychological stability is discussed in most of the religious development studies. It is also believed that children and adolescents that declare a religious entity demonstrate more prosocial behaviors and less likely to be involved in antisocial behavior. The literature reviewed also indicates that females are more intrinsically motivated and are more likely to conform to parents than males. Thus, based on these ideas, it is hypothesized that adolescents who report higher conformity to parental expectations will also report higher intrinsic and extrinsic religiosity.

Research also shows gender to be an important factor in the conformity to parental beliefs and religiosity. Minimal research has focused on the variable of biological sex however many studies show that there are differences in which the mother and father influence the development of the adolescent. Many studies find significant 
findings in which females show higher levels of conformity and intrinsic religiosity and males report higher levels of extrinsic religiosity.

Hypotheses

$\mathrm{H}_{1}$ : Female adolescents who report higher conformity to mothers will also report higher intrinsic religiosity.

$\mathrm{H}_{2}$ : Female adolescents who report higher conformity to mothers will also report lower levels of extrinsic religiosity.

$\mathrm{H}_{3} \quad$ Female adolescents who report higher conformity to fathers will also report lower levels of intrinsic religiosity.

$\mathrm{H}_{4} \quad$ Female adolescents who report higher conformity to fathers will also report higher extrinsic religiosity

$\mathrm{H}_{5}$ : Male adolescents who report higher conformity to mothers will also report higher intrinsic religiosity.

$\mathrm{H}_{6}$ : Male adolescents who report higher conformity to mothers will also report lower levels of extrinsic religiosity.

$\mathrm{H}_{7}$ : $\quad$ Male adolescents who report higher conformity to fathers will also report lower levels of intrinsic religiosity.

$\mathrm{H}_{8}$ : $\quad$ Male adolescents who report higher conformity to fathers will also report higher extrinsic religiosity. 


\section{Chapter Three}

\section{Methodology}

This study used data from an existing longitudinal study conducted by Dr.

Carolyn Henry and Dr. Linda Robinson (See Appendix A for investigator consent for data-set use). The Oklahoma State University Institutional Review Board was responsible for ensuring that ethical procedures were used during collection of the data. Data was entered using an alphanumeric system to match subjects between data collection points. However, participant's names and code numbers were kept separate from the data. Thus, the data set is de-identified.

\section{Sample}

This data set contains information from adolescents about characteristics of their families, community, and developmental well-being. Adolescents participating in this study were high school students attending the only public high school in each of three non-metropolitan communities (population less than 25,000). These communities were selected to be relatively equivalent in terms of selected indicators of community economic well-being, such as employment rate, rate of high school graduation, rates of post-high school education, and percentage of youth remaining in or returning to the area. These indicators were selected based on a review data from the US Census Bureau for overall community characteristics where the majority of Oklahoma's residents live. Thus, these communities are relatively representative of the general state population.

Demographics were run for the total available sample and a sub-sample selected for study inclusion as described below. Descriptive for each stage of the sampling is 
Table 1

Demographics for Sample and Proposed Sub-Sample

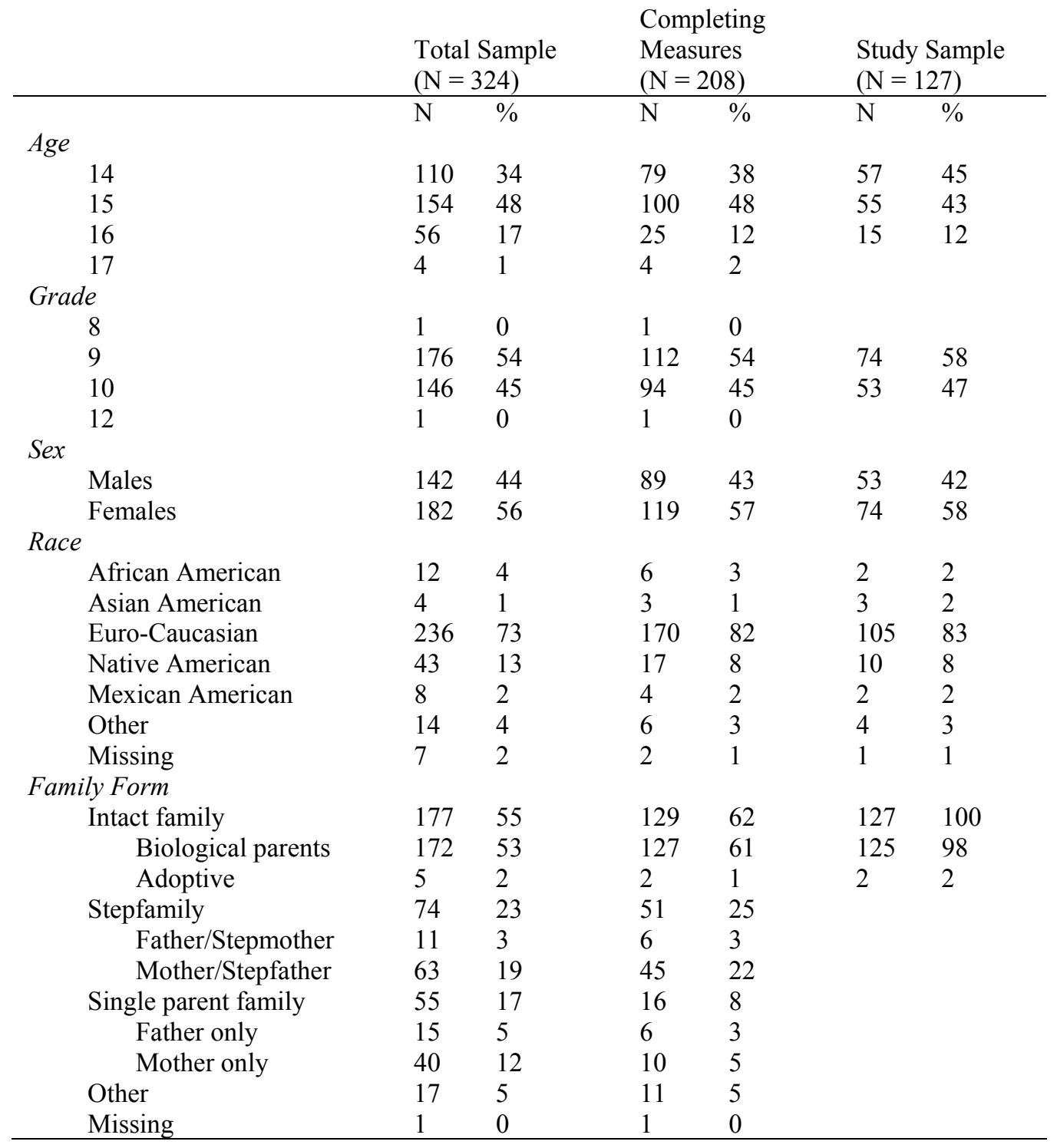

presented in Table 1. Participants in the sub-sample ranged in age from 14 to 16 years old $(M=14.81)$ and were divided into $74(58 \%) 9^{\text {th }}$ grade students and $53(47 \%) 10^{\text {th }}$ grade students. The sample was composed of $53(42 \%)$ males and $74(58 \%)$ females. The reported ethnicity of the sample was: 2 (2\%) African Americans, 3 (2\%) Asians, 105 (83\%) Caucasians, $10(8 \%)$ Native Americans, 2 (2\%) Mexican Americans, and 4 (3\%) 
students reporting "Other" or not providing any information. Additionally, this study used data from participants who reported residing in intact families, with 125 (98\%) reporting residence with both of their biological parents and $2(2 \%)$ with both adoptive parents. The decision to focus solely on children in intact families was made to control for possible effects of family form as an intervening variable (see details below).

\section{Procedures}

Participating adolescents were identified for sample inclusion based on their enrollment in local public high schools. To identify adolescents for sample inclusion, each school's administration was asked to identify courses which typically include freshman and sophomore students (e.g., $9^{\text {th }}$ and $10^{\text {th }}$ grade English). Participants were then contacted within the identified courses. Data collection then occurred during a subsequent visit to the identified class. One result of this approach was that in some instances the identified class contained adolescents who were enrolled in the course, but were not freshmen and sophomores. These students were excluded from the present study. Additionally, information was used only by students that completed each of the scales below.

\section{Measurements}

The self-report instruments were composed of standard fact sheets to obtain demographic data and existing instruments.

Conformity to parents. Adolescent reports of conformity to mothers and fathers was assessed using the 9 item Conformity sub-scale of the Parenting Behaviors Measure (Peterson et al., 1985). Participants were asked to respond to each item twice, once for 
mothers and once for fathers, on a 5' point Likert scale that ranged from $1=$ strongly disagree to $5=$ strongly agree. Two sample items from this scale were "If this parent wanted me to go around with a particular group of friends, then I would do as this parent wants me to (item 4), and "Generally speaking, I believe that I do most things in the way this parent wants me to (item 9). Based on the current data, internal consistency reliabilities were .75 for both scales.

Religiosity. Adolescent reports of intrinsic and extrinsic religiosity were assessed using an $11^{\prime}$ item modified versions of scales initially developed by Gorsuch and Venable (1983), and extended one' item by Schumm, Hatch, Hevelone, and Schumm (1991). Schumm et al. (1991) added an item to assess a specifically Christian intrinsic religiosity. All other items generalize to any faith that accepts God or the Bible. Participants were asked to respond to each item using a 5' point Likert scale that ranged from $1=$ strongly disagree to $5=$ strongly agree. Sample items from this scale include: "Although I am religious, I don't let it affect my daily life" (extrinsic) and "I try hard to live all my life according to my religious beliefs" (intrinsic). Based on the current data, internal consistency reliabilities were .65 for extrinsic religiosity and .81 for intrinsic religiosity.

Analysis

Scholarship on adolescent conformity to parental expectations indicate differences between adolescent girls and adolescent boys in relation to their conformity to their fathers and mothers. Thus, the analyses examined extrinsic and intrinsic religiosity in relation to adolescents' conformity to their mothers and their fathers separately as well as 
interactions between adolescent sex and conformity to each parent. Before analyzing the data, sex was dummy coded where $0=$ boys and $1=$ girls. Analyses consisted of bivariate analyses and 4 multiple regressions to test for interaction effects using procedures recommended by Aiken and West (1991) and Holmbeck (1997). The two models for each type of religiosity included adolescent biological sex (sex), conformity to mothers or fathers, and interaction effects for sex and conformity to mothers or fathers. 


\section{Chapter Four \\ Results}

Central tendencies and other summary statistics were first computed for each variable (see Table 4). Next, each continuous variable was centered on their respective means. Correlations and descriptives for each variable were computed for the study. (see Table 4) Sex demonstrated a single significant relation with extrinsic religiosity $(r=-$ $283, p<.01)$. Intrinsic religiosity was significantly correlated with both adolescent reports of conformity to mothers and fathers (respectively: $r=.30, p<.01 ; r=.378, p<.01$ ). Due to the hypothesized relations and the partially supported patterns of relations, each variable was retained in further analyses.

\section{Table 4}

Correlations and Variable Descriptives $(N=127)$

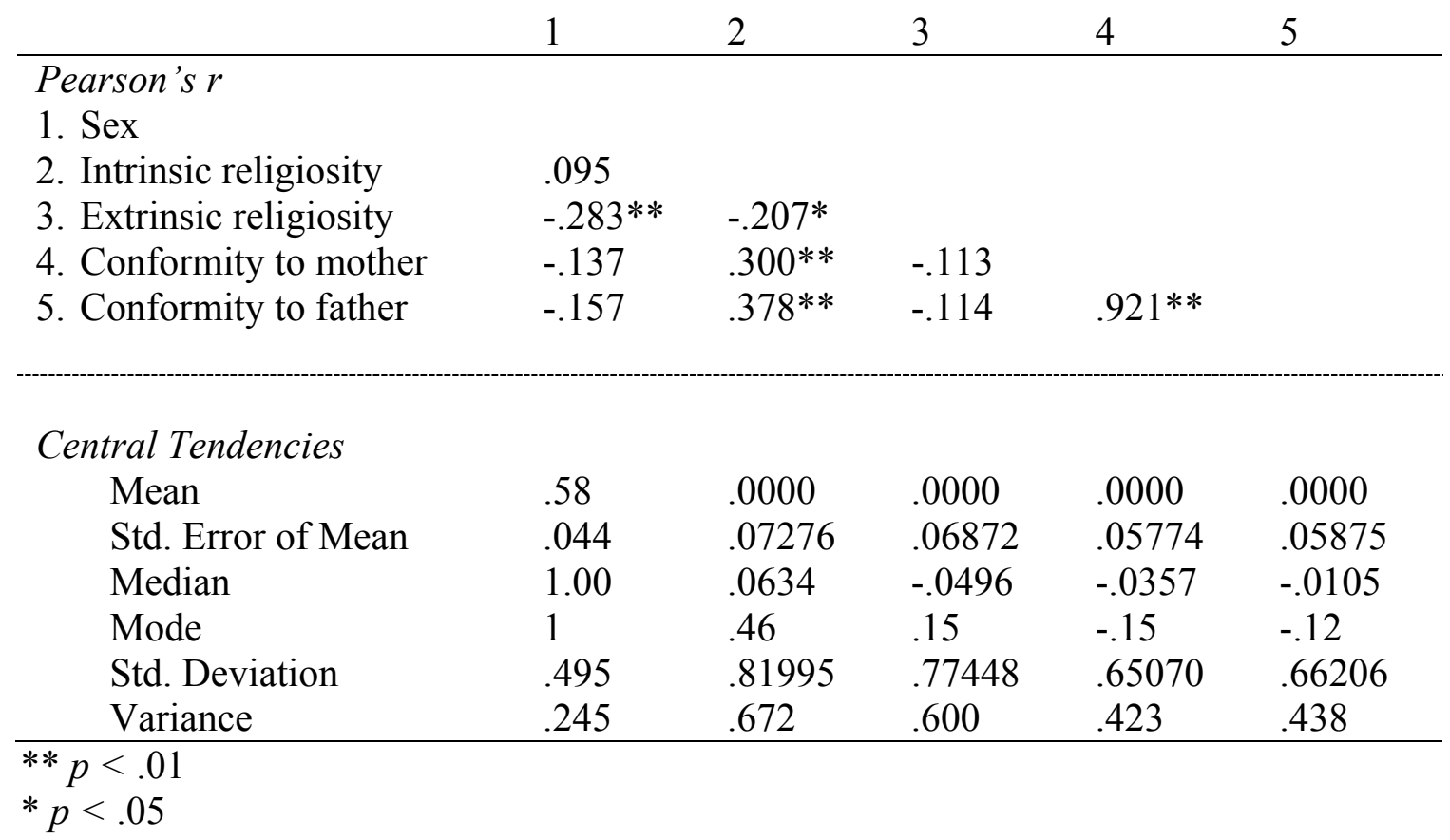




\section{Table 5}

\section{Sub-sample ANOVA's Comparing Family Form Differences on Each Variable}

\begin{tabular}{lllllll} 
Variable & & SS & $d f$ & $M S$ & $F$ & Sig. \\
\hline Extrinsic & Between & 3.309 & 3 & 1.103 & 1.773 & .154 \\
religiosity & Within & 126.306 & 203 & .622 & & \\
& Total & 129.615 & 206 & & & \\
Intrinsic & Between & 3.190 & 3 & 1.063 & 1.476 & .222 \\
Religiosity & Within & 146.219 & 203 & .720 & & \\
& Total & 149.409 & 206 & & & \\
Conformity to & Between & 5.060 & 3 & 1.687 & 3.487 & .017 \\
mother & Within & 98.199 & 203 & .484 & & \\
& Total & 103.258 & 206 & & & \\
Conformity to & Between & 7.674 & 3 & 2.558 & 4.954 & .002 \\
father & Within & 104.821 & 203 & .516 & & \\
& Total & 112.496 & 206 & & & \\
\hline
\end{tabular}

Checking Family Form as a Potential Intervening Variable

Prior to the regression analyses, possible group differences on key variables related to sub-sample were examined for possible biases. This was done to examine the validity of controlling for family form using the total sample of participants completing all measurements $(\mathrm{N}=208$; see Table 1 for sample description). Four ANOVA's (results are presented in Table 5) with Tukey's post-hoc's (results are presented in Table 6) were performed using family form as a fixed factor. This was done instead of a MANOVA due to sample differences and distributions relative to adolescent's reporting residence in single parent, remarried, and intact families (for further discussion see Stevens, 1996). The results proved to be non-significant for intrinsic and extrinsic religiosity. Thus, subsampling would not make a difference on Family Form relative to the dependent variables. However, ANOVA's for conformity to mothers and fathers did demonstrate significant differences between family forms. In further analyses using Tukey's HSD post-hocs, the comparisons indicated significant differences between existed for step and intact families. Specifically, adolescents reporting residence in intact families also 


\section{Table 6}

\section{Sub-sample Tukey HSD Comparing Family Form Differences on Conformity to Mothers and Fathers}

\begin{tabular}{|c|c|c|c|c|c|c|}
\hline \multirow{2}{*}{$\begin{array}{c}\text { Dependent Variable } \\
\text { Family form (I) }\end{array}$} & \multirow[b]{2}{*}{ Family form $(\mathrm{J})$} & \multirow[b]{2}{*}{$M_{d i f}(\mathrm{I}-\mathrm{J})$} & \multirow[b]{2}{*}{$S E$} & \multirow[b]{2}{*}{ Sig. } & \multicolumn{2}{|c|}{ Confidence Interval } \\
\hline & & & & & Lower & Upper \\
\hline \multicolumn{7}{|l|}{ Conformity to mother } \\
\hline \multirow{3}{*}{ Single parent family } & Intact family & -.18961 & .18435 & .733 & -.6671 & .2879 \\
\hline & Stepfamily & .13394 & .19930 & .908 & -.3823 & .6502 \\
\hline & Other & .23398 & .27241 & .826 & -.4717 & .9397 \\
\hline \multirow[t]{2}{*}{ Intact family } & Stepfamily & $.32354 *$ & .11504 & .027 & .0255 & .6216 \\
\hline & Other & .42359 & .21846 & .215 & -.1423 & .9895 \\
\hline Stepfamily & Other & .10004 & .23122 & .973 & -.4989 & .6990 \\
\hline \multicolumn{7}{|l|}{ Conformity to father } \\
\hline \multirow[t]{3}{*}{ Single parent family } & Intact family & -.08140 & .19046 & .974 & -.5748 & .4120 \\
\hline & Stepfamily & .31427 & .20591 & .424 & -.2191 & .8477 \\
\hline & Other & .45960 & .28145 & .362 & -.2695 & $1.188^{\prime}$ \\
\hline \multirow[t]{2}{*}{ Intact family } & Stepfamily & $.39567 * *$ & .11886 & .006 & .0878 & .7036 \\
\hline & Other & .54099 & .22571 & .081 & -.0437 & $1.125^{\circ}$ \\
\hline Stepfamily & Other & .14533 & .23889 & .929 & -.4735 & .7641 \\
\hline
\end{tabular}

$* p<.05 ; * * p<.01$

reporting higher conformity to both mothers and fathers $\left(\mathrm{M}_{\mathrm{dif}}=.32354 ; p=.027 ; \mathrm{M}_{\mathrm{dif}}=\right.$ $.39567 ; p=.006$ respectively). This indicated that family form is a potential intervening variable on these two variables and required control in subsequent analyses.

Intrinsic Religiosity Regressions

In the mother's model, the regression significantly $(p<0.00)$ explained $14 \%$ of intrinsic religiosity's total variance $\left(\operatorname{Adj} . R^{2}=.11\right)$. In this model, intrinsic religiosity was significantly related to Sex X Conformity $(\beta=.30 ; p<.05)$. However, intrinsic religiosity was not significantly related to either adolescent biological $\operatorname{sex}(\beta=.12)$ or adolescent conformity to mothers $(\beta=.06)$. Next, the father's regression model significantly $(p<0.00)$ explained $19 \%$ of intrinsic religiosity's total variance $\left(\right.$ Adj. $R^{2}=$ .17). In this model, intrinsic religiosity was significantly related to Sex X Conformity 


\section{Table 5}

Adolescent Intrinsic and Extrinsic Regression Models (N=127)

\begin{tabular}{|c|c|c|c|c|c|c|c|c|c|c|c|c|c|c|}
\hline \multirow[b]{2}{*}{$\begin{array}{r}\text { Outcome } \\
\text { Model } \\
\end{array}$} & \multirow[b]{2}{*}{$b$} & \multirow[b]{2}{*}{$S E$} & \multirow[b]{2}{*}{$B$} & \multirow[b]{2}{*}{ Sig. } & \multicolumn{3}{|c|}{ Correlations } & \multicolumn{7}{|c|}{ Model Summary } \\
\hline & & & & & $\begin{array}{l}\text { Zero- } \\
\text { order }\end{array}$ & Partial & Part & $R$ & $R^{2}$ & Adj. $R^{2}$ & $S E$ & $\mathrm{df}$ & $\mathrm{F}$ & Sig. \\
\hline \multicolumn{15}{|l|}{ Intrinsic Religiosity } \\
\hline \multicolumn{15}{|l|}{ Mother's Model } \\
\hline (Constant) & -.10 & .11 & & & & & & .37 & .14 & .11 & .77 & 3,123 & 6.44 & .00 \\
\hline Conformity & .08 & .20 & .06 & .70 & .30 & .04 & .03 & & & & & & & \\
\hline Sex & .21 & .14 & .12 & .15 & .09 & .13 & .12 & & & & & & & \\
\hline Sex X Conformity & .46 & .24 & .30 & .05 & .35 & .17 & .16 & & & & & & & \\
\hline \multicolumn{15}{|l|}{ Father's Model } \\
\hline (Constant) & -.11 & .11 & & & & & & .44 & .19 & .17 & .75 & 3,123 & 9.79 & .00 \\
\hline Conformity & .17 & .19 & .14 & .38 & .38 & .08 & .07 & & & & & & & \\
\hline Sex & .23 & .14 & .14 & .09 & .09 & .15 & .14 & & & & & & & \\
\hline Sex X Conformity & .45 & .23 & .31 & .05 & .41 & .18 & .16 & & & & & & & \\
\hline \multicolumn{15}{|l|}{ Extrinsic Religiosity } \\
\hline \multicolumn{15}{|l|}{ Mother's Model } \\
\hline (Constant) & .30 & .10 & & & & & & .34 & .11 & .09 & .74 & 3,123 & 5.22 & .00 \\
\hline Conformity & -.37 & .19 & -.31 & .06 & -.11 & -.17 & -.16 & & & & & & & \\
\hline Sex & -.49 & .13 & -.31 & .01 & -.28 & -.31 & -.31 & & & & & & & \\
\hline Sex X Conformity & .26 & .22 & .18 & .26 & -.06 & .10 & .10 & & & & & & & \\
\hline \multicolumn{15}{|l|}{ Father's Model } \\
\hline (Constant) & .30 & .10 & & & & & & .34 & .11 & .09 & .74 & 3,123 & 5.21 & .00 \\
\hline Conformity & -.35 & .19 & -.30 & .07 & -.11 & -.16 & -.16 & & & & & & & \\
\hline Sex & -.50 & .14 & -.32 & .01 & -.28 & -.31 & -.31 & & & & & & & \\
\hline Sex X Conformity & .22 & .23 & .16 & .32 & -.07 & .09 & .08 & & & & & & & \\
\hline
\end{tabular}




\section{Figure 1}

Sex X Conformity to Mothers Interaction on Intrinsic Religiosity

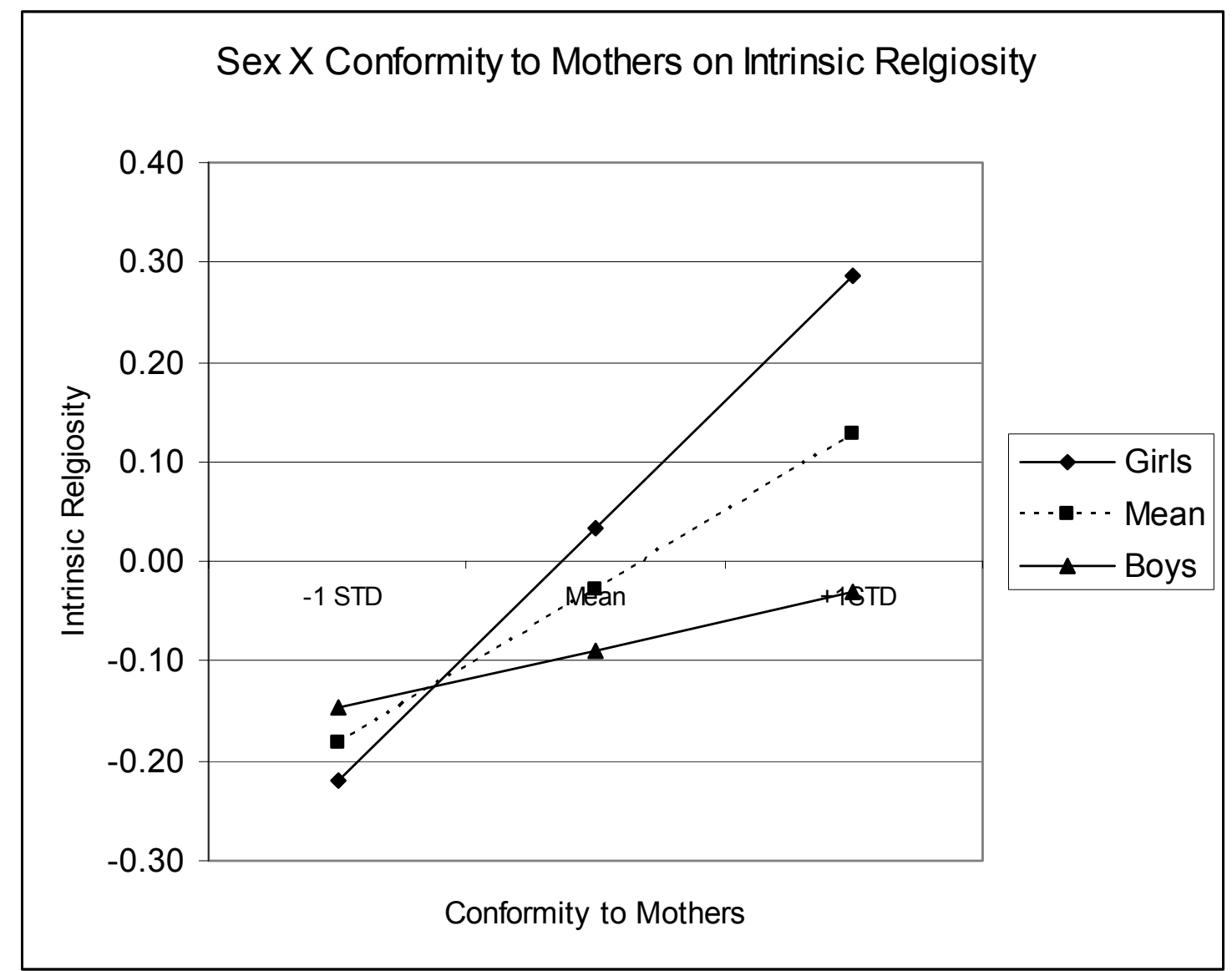

$(\beta=.31 ; p<.05)$. However, intrinsic religiosity was not significantly related to either adolescent biological sex $(\beta=.14)$ or adolescent conformity to mothers $(\beta=.14)$.

\section{Extrinsic Religiosity Regressions}

Alternately, in the mother's model for extrinsic religiosity $11 \%\left(\operatorname{Adj} . R^{2}=.09\right)$ of the total variance was significantly explained $(p<0.01)$. In contrast to the model for intrinsic religiosity, extrinsic religiosity was significantly related to $\operatorname{sex}(\beta=-.31 ; p<$ $0.00)$. Yet, in this model neither adolescent conformity to mothers $(\beta=-.31)$, nor the 


\section{Figure 2}

Sex X Conformity to Fathers Interaction on Intrinsic Religiosity

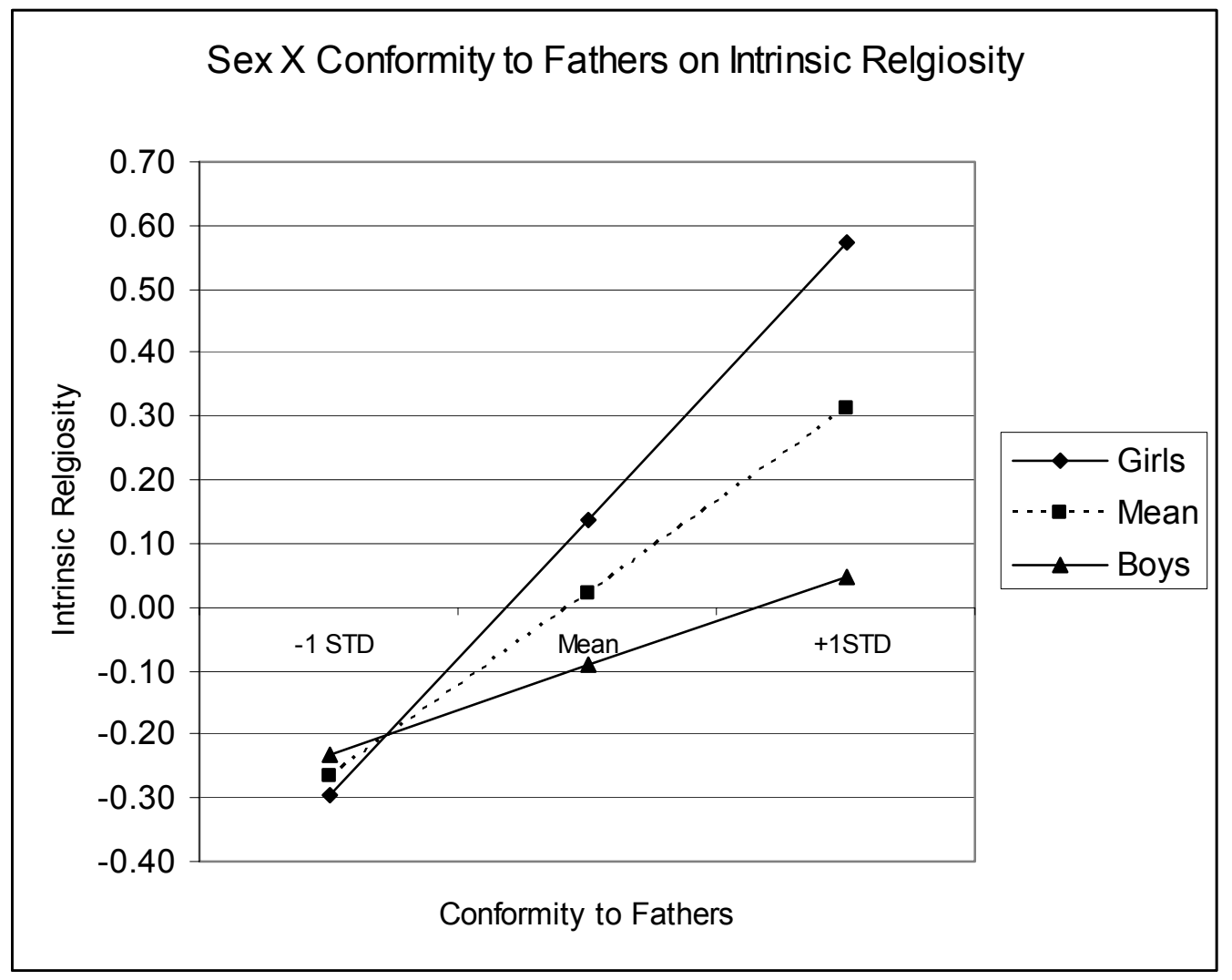

interaction between adolescent sex $\mathrm{X}$ conformity to mothers $(\beta=.18)$, were significantly related to extrinsic religiosity.

Similarly, in the father's model for extrinsic religiosity $11 \%\left(\operatorname{Adj} . R^{2}=.09\right)$ of the total variance was significantly explained $(p<0.01)$. Also in this model, extrinsic religiosity demonstrated a significant relation with to $\operatorname{sex}(\beta=-.31 ; p<0.01)$, but not with either adolescent conformity to fathers $(\beta=.30)$, nor the interaction for adolescent sex $\mathrm{X}$ conformity to fathers $(\beta=.16)$. 


\section{Analyzing the Interactions}

Significant interactions for Sex X Conformity to Mothers and Fathers on Intrinsic Religiosity were plotted and their slopes analyzed using procedures described by Aiken and West (1991). The equations were graphed for the relation between reported conformity to mothers and reports of intrinsic religiosity at three levels: the group average (the mean) female adolescent (girls) and male adolescent (boys). Summary statistics of the slope analyses, are presented in Table 6 . In general the results indicate that as girls reported higher level of conformity to mothers $(\mathrm{B}=.39)$ and fathers $(\mathrm{B}=.66)$ they also reported significantly higher levels of intrinsic religiosity. Alternately, as boys reported higher level of conformity to mothers $(\mathrm{B}=.09)$ and fathers $(\mathrm{B}=.21)$ they also reported higher, but non-significant, levels of intrinsic religiosity. Analyses of the slope differences indicated a significance difference between males and females $(t(123)=2.83$, $\mathrm{p}<.01)$. Thus, results indicate that as conformity to mothers and fathers increases for girls, intrinsic religiosity also significantly increased. In contrast, for boys increases in conformity to mothers and fathers was not accompanied by significant increases in intrinsic religiosity.

\section{Table 6}

\section{Slope Significance Tests for Intrinsic Religiosity}

\begin{tabular}{llll} 
Slopes Examined & t- value & df & Sig. $^{{ }^{a}}$ \\
\hline $\begin{array}{l}\text { Conformity to Mothers for Levels of Sex Differences } \\
\text { Girls }\end{array}$ & 2.83 & 123 & 0.01 \\
$\quad$ Boys & 0.49 & 123 & NS $^{\mathrm{b}}$ \\
& & & \\
Conformity to Fathers for Levels of Sex Differences & & & \\
$\quad$ Girls & 5.08 & 123 & 0.01 \\
$\quad$ Boys & 1.19 & 123 & NS \\
\hline
\end{tabular}

${ }^{\mathrm{a}}$ Based on tabled t-values from Aiken \& West (1991) with $d f=100$.

${ }^{\mathrm{b}} \mathrm{NS}=$ non-significant 


\section{Chapter Five}

Discussion

The purpose of this study was to examine adolescent conformity to mothers and fathers in relation to their religious development with a possible moderator effect of adolescent biological sex. Religiosity was operationalized using self-reports on measure for intrinsic and extrinsic religious orientation. Conformity to parents was measured using adolescents' self-reports of how much they conformed to their parents expectations for their education, behavior, and future goals. In general, the data demonstrates that the relation between adolescents' intrinsic religiosity and conformity to both mothers and fathers is moderated by the sex of the adolescent.

Based on previous research, eight separate hypotheses were advanced:

H1: Female adolescents who report higher conformity to mothers will also report higher intrinsic religiosity.

H2: Female adolescents who report higher conformity to mothers will also report lower levels of extrinsic religiosity.

H3: Female adolescents who report higher conformity to fathers will also report lower levels of intrinsic religiosity.

H4: Female adolescent who report higher conformity to fathers will also report higher extrinsic religiosity.

H5: Male adolescents who report higher conformity to mothers will also report higher intrinsic religiosity.

H6: Male adolescent who report higher conformity to mothers will also report lower levels of extrinsic religiosity. 
H7: Male adolescents who report higher conformity to fathers will also report lower levels of intrinsic religiosity.

H8: Male adolescent who report higher conformity to fathers will also report higher extrinsic religiosity.

These hypotheses were drawn from a common set of ideas based on previous research. First, research looking at female adolescents indicates that they report higher intrinsic religiosity as well as being influenced more than males by their mother's values (Flor \& Knapp, 2001). Additionally, research also suggests that adolescent females are more likely to conform to their mother's religious practices and values that their father's (Francis \& Gibson, 1993). Further, research also indicates that females in general, which would include mothers, generally report higher levels of intrinsic religiosity and values related to intrinsic religiosity,

Alternately, the gender intensification hypothesis suggests that as adolescents construct their gender roles there is increased pressure to conform to traditional ideas related to masculinity and femininity (Hill \& Lynch, 1983). In general, these are often based on parents' expectations of appropriate behaviors and values for adult males and females (Steinmetz, 1999). Based on the existing research (i. e., Donahue, 1985; King \& Boyatzis, 2004), intrinsic religiosity is more often associated with masculinity. Thus, the gender intensification hypothesis suggests that increased expectations of values related to intrinsic religiosity would exist for adolescent females while increased expectations of values related to intrinsic religiosity would exist for adolescent males. 
Additionally, research also indicates that extrinsic religiosity appears to involve lower demands of religious maturity (Bergin, Master, \& Richardso, 1987), while intrinsic religiosity appears to make more maturity demands on a child (Markstrom \& Smith, 1996). Thus it is reasonable to expect that if an adolescent reports a higher level of intrinsic religiosity, they he or she would rely less of extrinsic motivations.

From a symbolic interaction perspective, if parents have previously emphasized religious values and behaviors as being more important for either males or females in previous interactions, then it would be expected that this socialization would encourage greater religious maturity. Thus, adolescent females generally would be expected to have higher levels of intrinsic religiosity due to its linkages with femininity while males would have higher levels of extrinsic religiosity due to its linkages with masculinity. This also suggests that conformity to parental expectations would also lead to higher levels of intrinsic religiosity when an adolescent conforms to their mothers and higher levels of extrinsic religiosity when adolescent conforms to their fathers. However, it is important to note that parent's personal gender role ideology may complicate this scenario (Erickson, 2005).

\section{Adolescent Females and Their Conformity to Mothers Expectations}

Based on all previous research, it was expected that adolescent females who report higher conformity to mothers would also: (a) report higher intrinsic religiosity and (b) report lower levels of extrinsic religiosity (e.g. Hypothesis 1 and Hypothesis 2 respectively). In the analysis, Hypothesis 1 was supported by finding indicating that adolescent females who report higher conformity to mothers report higher intrinsic 
religiosity (Figure 1). This finding is similar to the work of Francis and Gibson's (1993) where adolescent females reported being more likely to conform to a mother's religious practice than to a father's. These results also supported several previous findings where female adolescent reporting higher intrinsic religiosity (Donahue, 1985; Milesvsky \& Leveit, 1004; Flor \& Knapp, 2001). This suggests, then, that conformity to mother's expectations may play a role in developing and internalizing the meanings attached to religious behaviors. From a symbolic interaction perspective, conformity to mother's expectations may reflect part of the internalization process related to mother's values for intrinsic religiosity. Thus, as adolescent females start to accept their mothers expectations they also may also be internalizing information that contributes to their development of intrinsic religiosity.

Hypothesis 2 emphasized that daughters who conform to their mothers should report lower levels of extrinsic religiosity. The finding here demonstrate that there were no significant relations for conformity to mother's expectations and extrinsic religiosity or for the interaction between sex and conformity to mother's expectations (see Table 5). The findings suggest conformity to mother's expectations neither increase, nor decrease, extrinsic religiosity. This is despite extrinsic religiosity's conceptual link to external religious behavior as being motivated desires to comply with external motivations (e.g.m Allport \& Ross, 1967; Donahue, 1985). In turn, this indicates that the relations between conformity to others expectations and extrinsic religiosity require further attention. 


\section{Adolescent Females and Their Conformity to Fathers Expectations}

The basis of Hypotheses 3 and 4 (respectively) was that female adolescent when conforming to fathers were expected to report lower levels of intrinsic religiosity, while at the same time, expected to report higher levels of extrinsic religiosity. This was augmented by research indicating that adolescent females who experience relationships with a parent that are more open and communicative are more likely to internalize the parent's religious beliefs (Flor \& Knapp, 2001). This is consistent with other research indicating that when adolescent perceive relationships with their parents as being closer and they also feel more supported and less controlled by their parents (Henry, Robinson, Neal, \& Huey, in press). Therefore, closeness in the parent-adolescent relationship also would allow genuine conformity versus forced compliance (i.e., Peterson et al., 1985). However, research has also indicated that fathers provide less attention and more negative responses towards their daughters than their sons (Lanvers, 2004). Thus, there are empirically based reasons to expect that daughters would report lower levels of conformity to their fathers and that this would related to lower levels of intrinsic religiosity.

However, the specific hypothesis for testing this premise was not supported by our data. Specifically, when the data was examined to ascertain if female adoelsecents who report higher conformity to fathers also report lower levels of intrinsic religiosity, the interaction between adolescent sex and conformity to father's expectations was significantly related to higher intrinsic religiosity (See Figure 2). The finding here indicate that father's expectations apparently do play role in adolescent female's intrinsic religiosity. 
Possible explanations for this finding indicate that father-daughter relationships are probably more complex than the scope of this study. On one hand, this may be explained by the presence of fathers in this sample that encourage development of female's intrinsic religiosity by expressly providing social cues that emphasize its desirability for females. On the other hand, it may also involve adolescent females in the sample that desire a relationship with their fathers to the extent that they conform more to their expectations out of desire for proximity and relationship (for a discussion see Baumrind, Henry, Wilson, \& Peterson, 1989) while intrinsic religiosity is merely an artifact of feminine socialization. Alternately, it may also reflect a situation where values and behaviors related to intrinsic religiosity also overlap with religious expectations for conformity to fathers (for a discussion see Ellison \& Sherkat, 1993).

Due to the nature of extrinsic religiosity as being more of an attempt to elicit favor from others based on their religious behavior (e.g., Paloutizian, 1996), it was hypothesized that female adolescent who report higher conformity to fathers will also report higher extrinsic religiosity (i. e., Hypothesis 4). It was reasoned that this would happen because daughters might be more likely to seek approval from their fathers through outwardly adhering to their expectations, which would spillover into their religious values. Yet, this hypothesis was also unsupported (see Table 5). One possible explanation for this is that fathers of females in this sample may have significantly varied in relation to their approaches to religion; thus, their communicated and socialized values may have also varied. However, the findings for intrinsic religiosity make it more likely that fathers of females in this sample may have emphasized more intrinsic dimensions of 
religiosity to the extent that it minimized the more extrinsic dimensions of religiosity. Again, though, this line of reasoning require data beyond what is here.

\section{Adolescent Males and Their Conformity to Mothers Expectations}

The reasoning behind Hypothesis 5 and Hypothesis 6 were also augmented by additional research. Building from the research underpinning Hypotheses 3 and 4 and the gender intensification hypothesis, it was reasoned that male adolescents who report higher conformity to mothers would also report higher levels of intrinsic religiosity and lower levels of extrinsic religiosity (i.e., Hypothesis 5 and Hypothesis 6 respectively). However, the findings here indicate that conformity to mother's expectations is not significantly related to adolescent males' religiosity (see Tables 5 and 6). Therefore, these analyses do not support these hypotheses and include only a significant relation for males reporting higher levels of extrinsic religiosity (see Tables 4 and 5), which are consistent with other research where adolescent males typically report higher extrinsic religiosity (e.g., Donahue 1985; Hardy \& Carlo, 2005).

\section{Adolescent Males and Their Conformity to Fathers Expectations}

Building again from ideas about gender intensification theory presented earlier, hypotheses 7 and 8 are premised on idea that adolescent males are socialized to be independent and assertive, unlike girls who are socialized to be expressive and compliant. These ideas are extended here by reasoning that that males in general are more likely to report higher levels of extrinsic religiosity. Therefore, it was expected that males who conform more to father's expectations would also report lower levels of intrinsic 
religiosity in the other (i.e., Hypothesis 7) and higher levels of extrinsic religiosity (i.e., Hypothesis 8). These hypotheses, though, are also consistent with previous research indicating that males in general report lower levels of intrinsic religiosity and higher levels of extrinsic religiosity. Additionally, previous research also indicates that males score higher on public prosocial behavior, or positive social behaviors motivated by social approval, rather than altruism when each were measured using a distinction similar to the differences in intrinsic and extrinsic religiosity (Hardy \& Carlo, 2005). When both hypotheses were tested, the results were non-significant (see Table 5).

However, when considered together with the findings for Hypotheses 5 and 6, this suggests that conformity to parents' expectations may play a lesser role in adolescent males religiosity than for females. Yet, a modest slope was detected in the analyses which indicates that there is a least a slight positive relation between the two variables. Therefore, it cannot be fully concluded that conformity to parental expectations are entirely unrelated to adolescent male religiosity. Instead, it may be that societal emphases on independence and autonomy as a masculine traits and religious based behaviors as a feminine traits may diminish the likelihood that adolescent males will conform to parental expectations or endorse religious based behaviors and values. Thus, further research is needed in order to produce significant findings. What can be concluded, though, from these findings is that adolescent males may require a different approach than what is used for females if parents wish to encourage development of religious values and behaviors.

Overall the findings suggest that significant differences exist for males and female religious development in relation to their conformity to parents. Generally, the findings 
indicate that adolescent females report higher levels of intrinsic religiosity and lower levels of extrinsic religiosity. Additionally, conformity to parent's expectations were nonsignificantly related to extrinsic religiosity. When looking ay the interactions between conformity to parental expectations and sex, it appears that as adolescent females report higher levels to either parent they also report higher levels of intrinsic religiosity. Thus, it is concluded that for adolescent females conformity to either mothers or fathers is probably an important facet of developing intrinsically motivated religious behaviors and values. For males, though, conformity to either parent was non-significantly related to intrinsic religiosity. Alternately, the only significant finding for extrinsic religiosity was that being female tended to be related with lower levels reports of extrinsic religiosity; thus, due to the equations used it appears that males reported higher levels of extrinsic religiosity. These findings, then, indicate that there is something more happening in regards to adolescent male religiosity as well as adolescent reports of extrinsic religiosity than was examined by this study.

\section{Limitations of the Study}

A major limitation of this study was that only intact families were used. This was done to control for sample heterogeneity, however, this limits the generalizability of the findings. Another major limitation of this study was that only self-report data was collected. In self-report data, there is no clear way to ensure the "truthfulness" of the responses, which creates an issue for validity. Further, it also can create a social desirability problem since they may only respond accordingly to how they thing the 
researchers want them to. As a result, the data in the study might not be completely accurate; thus, increasing the potential error in each equation.

Another limitation of this study was sample size. Due to the limited amount of participants the results were possibly skewed in relation to normal distribution. Thus, a larger sample size would have been desirable. Further this sample was only drawn from non-metropolitan areas, which neglects research suggesting family life in metropolitan areas.

Next, there is a current debate about how best to describe religious development. By relying on the intrinsic/extrinsic dichotomy it is possible that other pieces may have been missed. The question of how personal religion should be measured is still an ongoing debate. Batson and Schoenrade (1991) discuss the validity of the Quest scale which was introduced by Batson (1976) and Batson and Ventis (1982) and found that it does indeed measure a dimension of personal religion very much like the one it was designed to measure: an open-ended, active approach to existential questions that resists clearcut, pat answers. Additionally, this study did not include information about conformity to peers. Previous research, though, indicates that this is an important element in adolescent development of religiosity. Studies have shown that peer conformity dispositions (willingness to conform to peers) as well as conformity behavior increase from childhood through adolescence and is often considered one of the hallmarks of adolescent behavior (Brown, Clasen, \& Eicher, 1986). Erikson (1968) argued that the early adolescent's need for affiliation with a group of peers is manifested by conformity to group norms, and that the group itself is strengthened when members exert conformity pressures on each other. Conformity to peers that are religiously 
involved or part of a religious affiliation would in doubt influence an adolescent's belief and religiosity. Thus, it may serve as a potential intervening variable. Finally, this study did not assess gender role differences. Since sex does seem to be important in relation to adolescent conformity to parents, gender role development needs to be further researched in order to understand why this is. This study found that there is a difference between male and female internalization of religious beliefs and previous research indicates that it has something to do with the way males and females are socialized. Therefore, gender roles would be a potential intervening variable. Previous research states that females report higher intrinsic religiosity (Donahue, 1985; Milevsky \& Levitt 2004) than males, therefore it is assumed that gender development has some relation to religious development.

\section{Implications}

\section{Parenting}

The findings indicate that intrinsic religiosity, which in previous research is more desirable than extrinsic religiosity (Baker \& Gorsuch, 1982), relates to adolescent's reports of conformity to fathers and mothers and is moderated by the sex of the adolescent. The interaction effect seen between sex of the adolescent and conformity to mothers and fathers in each equation indicates that the more closely an adolescent aligns himself, or herself, with their parents expectations the higher their reports of intrinsic religiosity. While this effect is only significant in regards to females, the presence of modest upward slopes for (male i.e., mothers $\mathrm{B}=.09$ and fathers $\mathrm{B}=.21$ ) do suggest that 
this interpretation holds true for both adolescent boys and girls but should be cautiously interpreted.

From a symbolic interaction perspective, then, this suggests that parents interacting with their children should use strategies that help adolescents to understand what parents value and believe. Based on previous work on parenting, some pertinent behaviors that would encourage this are reasoning (Peterson \& Hann, 1999), positive induction (Hoffman, 1970; Peterson \& Leigh, 1990), or making rational maturity demands (Peterson \& Hann, 1999; Holmbeck et al., 1995). Despite differing theoretical value for each of these, overall emphasis is that when parents provide children with their reasons for the desirability of specific social behaviors and values, such as those related to religion, they encourage their children's development of internalized values and controls (Peterson, 1987). In turn, previous research on adolescents has linked parental behavioral pattern with higher levels of adolescent conformity (Baumrind, 1978; Durkheim, 1961; Henry, Wilson, \& Peterson, 1989). While this presents a potential confound, that is parents may emphasize a value for internalized conformity to their expectations, it also may establish a stronger base for late adolescent development of internalized religious values. This is because it may provide an understanding of what parents value, why they feel it is important, and standards of behavior-each of these having empirical validation relating to encouragement of parent-child interactions, development of desirable social behaviors (Hardy \& Carlo, 2005) and child well-being (Loury, 2004). 
However, research also indicates that children also modify their perceptions of information provided by their parents based on the behavior of the parent (Peterson, 1987). Further, adolescent children are also more likely to perceive hypocrisy when parents do not enact the behaviors that attempt to develop in the child (Holmbeck et al., 1995).Thus, we recommend that while parents spend time explaining to their children what they value, they also must model the desired behaviors. Stated more simply, they have to walk the walk and talk the talk.

Alternately, only the sex of the adolescent was related to differences in extrinsic religiosity. Due to previous research findings that intrinsic and extrinsic religiosity may have varying levels of value for males and females relative to societal gender roles (McHale, Crouter, \& Whiteman, 2003), these findings suggest parents may need to consider differing strategies for adolescent males and females to encourage adolescent religious development. Returning to the recommendations above, the interaction effect seen here are more significant for females. Thus, encouraging adolescent male intrinsic religiosity may require a different approach. Stated differently, a one size should fit all approach for developing intrinsic religiosity probably is ineffective. Instead, using the gender intensification hypothesis parents should probably consider using more strategies that encourage religious development as having masculine attributes. Thus, the internalized masculine social role values would contain desired elements for intrinsic religiosity. However, this could require some adaptation of current religious imagery that emphasizes values considered to be more feminine. 


\section{Adults Working With Adolescents in Religious Development}

While parents can use these findings, professionals working with adolescents in religious settings can also benefit from several aspects. Adults working with adolescents should consider implementing programs that are sex appropriate. In other words, since there is an obvious difference among girls and boys in they way they develop religious values, there should be alternative teaching methods for each. Based on the findings here, conformity to a male or female instructor maybe not as important to females as it is for males. However, findings indicate that intrinsic religiosity was not related to conformity to mothers or fathers. Thus it may be more important for adolescent males to have peer interactions to encourage their religious development. Therefore, classes that use a lecture approach may not work for males.

Second, biological sex differences and conformity to parental expectations appear to be interactive and related to intrinsic religiosity. Due to these findings here, professionals should probably strive to include both mothers and fathers in their programs. In part, this is because both parents have a unique influence on their children which contributes to religious development. Based on previous research, both of them are needed by adolescents to compare and contrast social information. Thus it may not be enough to rely on either mothers or fathers.

Third, the negative relation between extrinsic religiosity and parent conformity, while non-significant, does suggest that stressing what religion can give you is not a productive strategy for encouraging spiritual development. Instead, if parents really want to encourage development of religious values, they should not portray religion as a means 
of gaining rewards. For example, a child should not go to church expecting something in return. Parents should not influence their children into believing that if you are good or do good things then you will get your reward in heaven. Encouraging these ideas may actually counteract the initial goal of developing intrinsic religious values. In fact they are encouraging the development of extrinsic motivation.

\section{Research}

Religiosity tends to be a neglected topic in present research and needs to be further examined due to the significant findings of its influence on today's adolescent development (King \& Boyatzis, 2004). Due to these findings, future research should continue to examine these variables by studying more complex family models. In this particular study, it only focused on intact families however it would be desirable to look at more diverse family forms. Especially since many families and relationships create and form different meanings due to a variations from their unique life circumstances. For example, a single mother's relationship with her daughter or son might be expected to differ from a mother in an intact family. Studying relationships on a one on one basis would allow a closer examination of each variable. Researchers should also look at the unique dynamics the mother/daughter relationships and father/son relationships to gain closer understanding of what kind of interaction is occurring. In particular, this should move beyond questionnaires and use observation data and interviews.

Future research needs to expand by applying more complex models of parent socialization and family dynamics. Gender development and role ideology were not 
examined in this study, however future research should expand on these topics and focus on how sex differences relate to the socialization of these apparent differences in conformity and religious values. In particular, this study found that biological sex moderated conformity to parents, but these sex differences may only be a proxies for possible gender role issues. Thus it would probably be a good idea if gender roles were included as part of future project looking at adolescent conformity to their parents.

Additionally, it would be desirable for future research to focus longitudinally on transitions into, and through, adolescence. This would provide for indications of (a) when parent's expectations gain or loose importance, (b) when conformity to parents begins to change, as well as (c) how religion begins to influence their lives. In turn, this would help parents and teachers focus on making sure that at that time proper guidance and instruction could be implemented adaptively and in a timely manner.

This study was limited not only to the size of the sample but the area in which the sample was chosen from. To improve future research, studies should include a larger and more diverse sample. Notably, future research should involve collecting data from schools in metropolitan area(s) and include step families due to the present prevalence of divorce and re-marriage. Further, to address some of the conceptual issues above, this research should look at each parent, and child, individually. One to do this would be to give mothers and fathers directions for completing on single task. Then ask the parents to guide their child through the directions while others either observed or taped tem to determine how much the child conformed to the parents directions. Alternately, researchers could also interview mothers, fathers, and children on a consistent set of key topics. Once interviews were complete they could then be compared for similarities and 
differences in viewpoints; thus allowing for in depth in formation on where adolescents conformed with each parent's unique views. 


\section{References}

Aiken, L., \& West, S. (1991). Multiple regression: Testing and interpreting interactions. Newbury Park, CA: Sage.

Allport, G. W. (1959). Religion and prejudice. Crane Review, 2, 1-10.

Allport, G. W. (1966). Religious context of prejudice. Journal for the Scientific Study of Religion, 5,(3), 447-457.

Allport, G. W., \& Ross, J. M. (1967). Personal religious orientation and prejudice. Journal of Personality and Social Psychology, 5(4), 432-443.

Baker, M., \& Gorsuch, R. (1982). Trait anxiety and intrinsic-extrinsic religiousness. Journal for the Scientific Study of Religion, 21(2), 119-122.

Balk, D. (1983). How teenagers cope with sibling death: Some implications for school counselors. School Counselor, 31, 150-158.

Batson, C. D., \& Schoenrade, P. A. (1991). Measuring religion as quest: Validity concerns. Journal for the Scientific Study of Religion, 30(4), 416-429.

Batson, C. D., \& Ventis, W. L. (1982). The religious experience: A social-psychological perspective. New York: Oxford University Press.

Baumrind, D. (1978). Parental disciplinary patterns and social competence in children. Youth \& Society, 9, 239-276.

Beit-Hallahmi, B., \& Argyle, M. (1997). The psychology of religious behavior, belief, and experience. New York: Routledge.

Bergin, A. E., Master, K. S., \& Richards, P. S. (1987). Religiousness and mental health Reconsidered: A study of an intrinsically religious sample. Journal of Counseling Psychology, 34(2), 197-204. 
Blumer, H. (1969). Symbolic interactionism: Perspective and method. Berkeley, CA: University of California Press.

Bronfenbrenner, U. (1970). Two worlds of childhood: U.S. and U.S.S.R. New York: Russell Sage Foundation.

Brown, B. B., Clasen, D. R., \& Eicher, S. A. (1986). Perceptions of peer pressure, peer conformity dispositions, and self-reported behavior among adolescents. Developmental Psychology, 27(4), 521-530.

Brown, B.B., Lohr, M. J. (1987). Peer-group affiliation and adolescent self-esteem: An integration of ego-identity and symbolic-interaction theories. Journal of Personality and Social Psychology, 52(1), 47-55.

Bumpus, M. F., Crouter, A. C., \& McHale, S. M. (2001). Parental autonomy granting during adolescence: Exploring gender differences in context. Developmental Psychology, 37(2), 163-173.

Cherry, L. \& Lewis, M. (1976). Mothers and two-year olds: A study of sex-differentiated aspects of verbal interaction. Developmental Psychology, 12, 466-478.

Cornwall, M. (1989). Faith and development of men and women. In S. J. Bahr \& E. T. Peterson, (Eds.), Aging and the family (pp. 115-139). Lexington, MA: Lexington Books.

Denzin, N. (1985). Emotion as lived experience. Symbolic Interaction, 8, 223-240.

Donohue, M. J. (1985). Intrinsic and extrinsic religiousness: Review and meta-analysis. Journal of Personality and Social Psychology, 48(2), 400-419.

Duck, J. \& Fortey, K. (2003). The same yet different: The role of distinctiveness in adolescent conformity. Australian Journal of Psychology, 55, 41. 
Dudley, R. L. (1993). Indicators of commitment to the church: A longitudinal study of church-affiliated youth. Adolescence, 28(109).

Durkheim, E. (1961). Moral Education. New York: Free Press.

Elder, G. H. (1963). Parental power legitimation and its effect on the adolescent. Sociometry, 26, 50-65.

Erickson, E. H. (1959). Identity and the life cycle. Psychological Issues, 1, 18-164.

Erickson, E. H. (1968). Identity: Youth and crisis. New York: W. W. Norton \& Company.

Flor, D. L., \& Knapp, N. F. (2001). Transmission and transaction: Predicting adolescents' internalization of parental religious values. Journal of Family Psychology, 15(4), $627-645$.

Francis, L. J., \& Gibson, H. M. (1993). Parental influence and adolescent religiosity: A Study of church attendance and attitude toward Christianity among adolescents 11 to 12 and 15 to 16 years old. The International Journal for the Psychology of Religion, 3(4), 241-253.

Furrow, J. L., King, P. E., \& White, K. (2004). Religion and positive youth development: Identity, meaning, and prosocial concerns. Applied Developmental Science, 8(1), $17-26$.

Genia, V. (1996). I, e, quest, and fundamentalism as predictors of psychological and spiritual well-being. Journal for the Scientific Study of Religion, 35(1), 56-64.

Glenn, N. D. (1982) Interreligious marriages in the United States. Journal of Marriage and the Family, 44, 555-566. 
Goldblatt, H., \& Eisikovitz, Z. (2005). Role taking of youths in a family context: Adolescents exposed to interparental violence. American Journal of Orthopsychiatry, 75(4), 644-657.

Gorsuch, R. L., \& Venable, G. D. (1983). Development of an “age universal” I-E scale. Journal for the Scientific Study of Religion, 22, 181-187.

Gunnoe, M. L., \& Moore, K. A. (2002). Predictors of religiosity among youth aged 1722: A longitudinal study of the national survey of children. Journal for the Scientific Study of Religion, 41(4), 613-622.

Hardy, S. A., \& Carlo, G. (2005). Religiosity and prosocial behaviors in adolescence: The mediating role of prosocial values. Journal of Moral Education, 34,(2), 231-249.

Hayes, B. C., \& Pittlekow, Y. (1993). Religious belief, transmission, and the family: An Australian study. Journal of Marriage and the Family, 55, 755-766.

Hill, J. P., \& Lynch, M. E. (1983). The intensification of gender-related role expectations during early adolescence. In J. Brooks-Gunn \& A. C. Petersen (Eds.), Girls at puberty: Biological and psychosocial perspectives, 201-228. New York: Plenum.

Holmbeck, G. N. (1997). Toward terminological, conceptual, and statistical clarity in the study of mediators and moderators: Examples from the child-clinical and pediatric psychology literature. Journal of Consulting and Clinical Psychology, 65, 599610.

Holmbeck, G. N., Paikoff, R. L., \& Brooks-Gunn, J. (1995). Parenting Adolescent. In M. H. Bornstein (Ed.) Handbook of parenting, Vol. 1: Children and parenting (pp. 91-118). Hillsdale, NJ: Erlbaum : Lawrence Erlbaum Associates, Inc. 
Hunsberger, B., \& Brown, L. B. (1984). Religious socialization, apostasy, and the impact of family background. Journal for the Scientific Study of Religion, 23. 239-251.

Jenkins, K. W. (1992). Religion and families. Family research: A sixty-year review, 1930-1990 (Vol. 1, 235-288). New York: Lexington Books.

King, P. E., \& Boyatzis, C. J. 2004. Exploring adolescent spiritual and religious development: Current and future theoretical and empirical perspectives. Applied Developmental Science, 8(1), 2-6.

King, V., Elder Jr., G. H., \& Whitbeck, L. B. (1997). Religious involvement among rural youth: An Ecological and life-course perspective. Journal of Research on Adolescence, 7(4), 431-456.

Klein, D. M., \& White, J. M. (1996). Family Theories: An introduction. Thousand Oaks: SAGE Publications.

Krause, N., \& Van Tran, T. (1987). Stress and religious involvement among older blacks. Journal of Gerontology, 44, 504-513.

Lanvers, U. (2004). Gender in discourse behaviour in parent-child dyads: A literature review. Child: Care, Health \& Development, 30(5), 481-493.

LaRossa, R., \& Reitzes, D.C (1993). Symbolic interactionism and Family Studies. In P.G Boss, W.J. Doherty, R. LaRossa, W.R. Schumm, \& S.K. Steinmetz (Eds.), Sourcebook of family theories and methods: A contextual approach (pp. 135-162). New York: Plenum.

Learner, R. M. (1985). Adolescent maturational changes and psychosocial development: A dynamic interactional perspective. Journal of Youth and Adolescence, 14,(4), $355-372$. 
Loury, L. D. (2004). Does church attendance really increase schooling? Journal for the Scientific Study of Religion, 43(1), 119-127.

Luft, G. A., \& Sorell, G. T. (1987). Parenting style and parent-adolescent religious value consensus. Journal of Adolescent Research, 2(1), 53-68.

Mahoney, A. (2000). U.S. norms on religious affiliation, self-reported importance, and church attendance of mothers and fathers of children and adolescent: Secondary analyses of 1995 Gallup poll. Unpublished manuscript, Bowling Green State University.

Markstrom-Adams, C., \& Smith, M. (1994). Identity formation and religious orientation among high school students from the United States and Canada. Journal of Adolescence, (19), 247-261.

McGillicuddy-De Lisi, A. V. \& Sigel, I. E. (1995). Parental beliefs. In M. H. Bornstein (Ed.), Handbook of Parenting, Vol. 3: Status and social conditions of parenting (pp.333-358). Hillsdale, NJ, England: Lawrence Erlbaum Associates, Inc.

McHale, S. M., Crouter, A. C., \& Whiteman, S. D. (2003). The family contexts of gender development in childhood and adolescence. Social Development, 12(1), 125-148.

Meadow, M. J., \& Kahoe, R. D. (1984). Psychology of religion: Religion in individual lives. New York: Harper \& Row.

Milevsky, A., \& Levitt, M. (2004). Intrinsic and extrinsic religiosity in preadolescence and adolescence: Effect on psychological adjustment. Mental Health, Religion \& Culture, 7(2), 307-321. 
Ozorak, E. W. (1989). Social and cognitive influences on the development of religious beliefs and commitment in adolescence. Journal for the Scientific Study of Religion, 28(4), 448-463.

Paloutzian, R. F., (1996). Invitation to the psychology of religion ( $2^{\text {nd }}$ ed.). Needham Heights, MA: Allyn \& Bacon.

Peterson, G. W. (1982). Parent behavior measure. Unpublished manuscript. Knoxville, TN: University of Tennessee, Child and Family Studies.

Peterson, G. W. (1995). Autonomy and connectedness in families. In F. D. Day and W. R. Burr (Eds.) Advanced Family Science (pp. 20-41). New York: Brooks-Cole.

Peterson, G. W., Rollins, B. C., \& Thomas, D. L. (1985). Parental influence and adolescent conformity: Compliance and internalization. Youth and Society, 16, $397-420$.

Pomerantz, Eva M.; Ng, Florrie Fei-Yin; Wang, Qian; (2004). Gender Socialization: A Parent x Child Model. In, A. H. Eagly, A. E. Beall, R. J. Sternber, (Eds.) The psychology of gender ( $2^{\text {nd }}$ ed., pp. 120-144. New York: Guilford Press.

Powell, K. C. (2004). Developmental psychology of adolescent girls: Conflicts and identity issues. Education, 125(1), 77-87.

Regnerus, M., Smith, C., \& Fritsch, M. (2003). Religion in the lives of American adolescents: A research report of the national study of youth and religion. National Study of Youth and Religion, University of North Carolina at Chapel Hill. 
Rollins. B. C., \& Thomas, D. L. (1979). Parental support, power, and control in the socialization of children. In W. R. Burr, R. Hill, F. I. Nye \& I. R. Reiss (Eds.), Contemporary Theories about the Family: Vol. I (pp. 317-364). New York: Free Press.

Rosenberg, M. (1981). The self-concept: Social product and social force. In M.

Rosenberg \& R. Turner (Eds.), Social Psychology: Sociological Perspectives (pp. 593-624). New York: Basic Books.

Schumm, W. R., Hatch, R. C., Hevelone, J., \& Schumm, K. R. (1989). Attrition and retention among Christian Church (Disciples of Christ) congregations in three metropolitan regions: A mail survey of 1,149 active and inactive members. In D. N. Williams (Ed.), A case study of mainstream Protestantism: The Disciples' relation to American culture 1880-1989 (pp. 521-553). Grand Rapids, MI: Eerdmans.

Simmons, R. G. (1987). Self-esteem in adolescence. In T. Honess \& K. Yardley (Eds.), Self and identity: Perspectives across the lifespan (pp. 172-192). New York: Routledge \& Kegan Paul.

Spilka, B., Hood, Jr., R. W., Hunsberger, B., Gorsuch, R. (2003). The psychology of Religion. New York: Guilford Press.

Steinmetz, S. K. (1999). Adolescence in contemporary families. In M. B. Sussman, S. K. Steinmetz, G. W. Peterson, (Eds.) Handbook of marriage and the family $\left(2^{\text {nd }}\right.$ ed., pp. 371-423. New York: Plenum Press.

Stryker, S. (1964). The interactional and situational approaches. In H. Christianson (Ed.) Handbook of Marriage and the Family (pp. 124-170). Chicago: Rand McNally. 
Stryker, S. (1980). Symbolic interactionism: A structural version. Menlo Park, CA: Benjamin/Cummings.

Stryker, S. (1981). Symbolic interactionism: Themes and variations. In M. Rosenberg \& R. Turner (Eds.), Social Psychology: Sociological Perspectives (pp. 3-29). New York: Basic Books.

Turner, J. H. (1978). The Structure of Sociological Theory. Homewood, Ill.: Dorsey.

Weigert, A. J., Teitge, J. S., \& Teitge, D, W. (1986). Society and identity: Toward a sociological psychology. New York: Cambridge University Press.

Wong-McDonald, A. \& Gorsuch, R. L. (2004). A multivariate theory of God concept, religious motivation, locus of control, coping, and spriritual well-being. Journal of Psychology and Theology, 32(4), 318-334. 
APPENDIX A

Consent to Use Data 
$\begin{array}{ll}\text { From: } & \text { "Henry, Carolyn" <carolyn.henry@okstate.edu> } \\ \text { To: } & \text { <erron.huey@mail.wvu.edu> } \\ \text { Date: } & \text { 7/11/06 11:17PM } \\ \text { Subject: } & \text { Permission to use data for R. Summers' Thesis }\end{array}$

Dr. Huey,

I am writing to provide verification that I granted permission for you to direct Rebecca Kim Summers in completing her thesis using the "AES 97 Project" data collected through Oklahoma State University (Principal Investigators: Carolyn S. Henry and Linda C. Robinson).

As per our verbal agreement, Dr. Robinson and I want to be involved as authors on all conference papers or manuscripts submitted emerging the thesis. I am happy to assist with the papers or manuscripts as needed.

I am pleased Ms. Summers is completing her thesis and degree and hope that the use of the data is a valuable professional development experience for her.

ch

Carolyn S. Henry, Ph.D.

Professor

Dept. of Human Development \& Family Science

Oklahoma State University

Stillwater, OK 74078-6122

Phone: (405) 744-8357

Fax: (405) 744-2800

email: carolyn.henry@okstate.edu 


\section{APPENDIX B}

Population Comparisons: State Population and

General Study Sample 
Demographics Comparison of Population Characteristics Based on US Census 1990 Data and Reported Sample Demographics

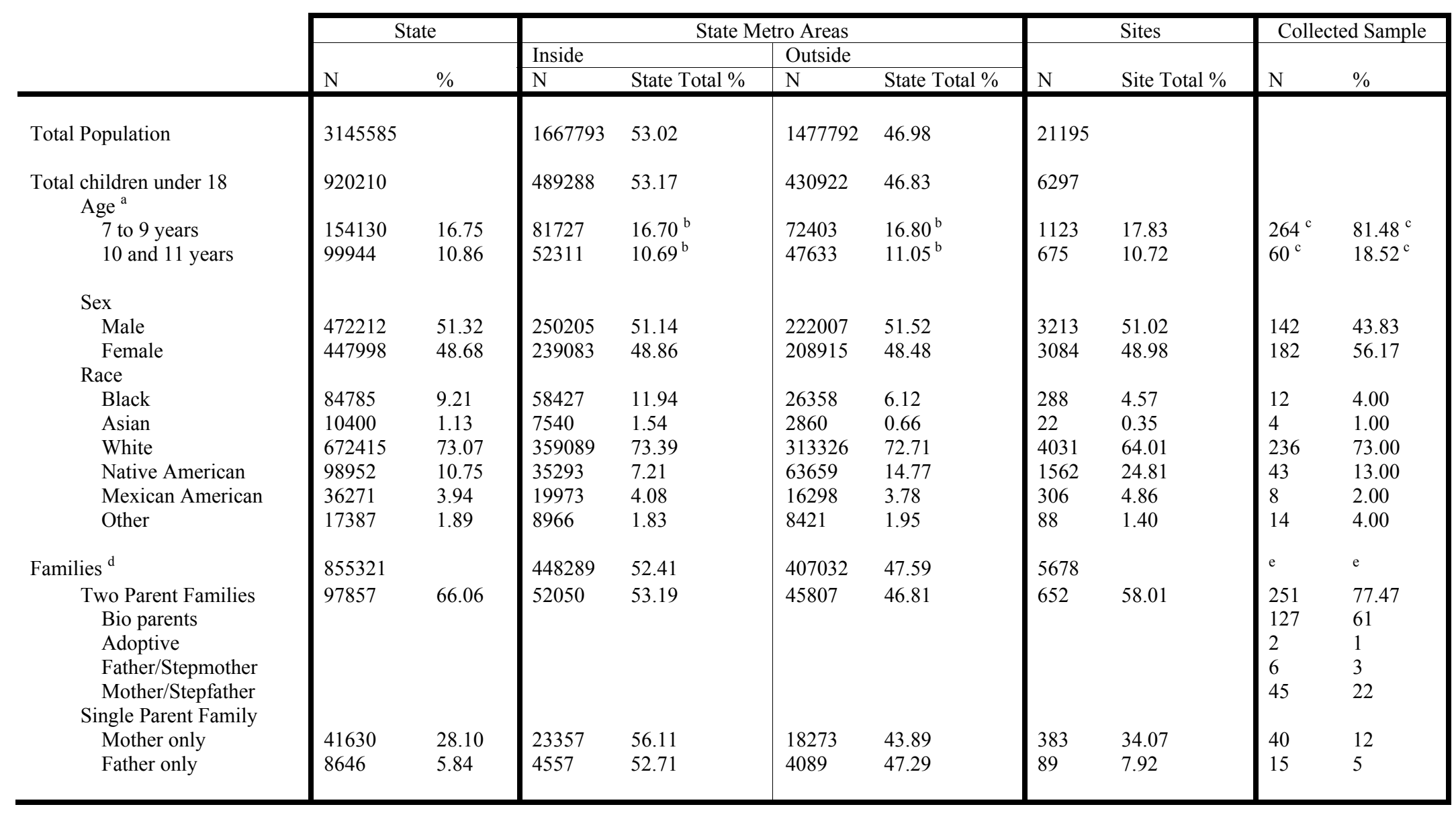


Demographics Comparison of Population Characteristics (Continued)

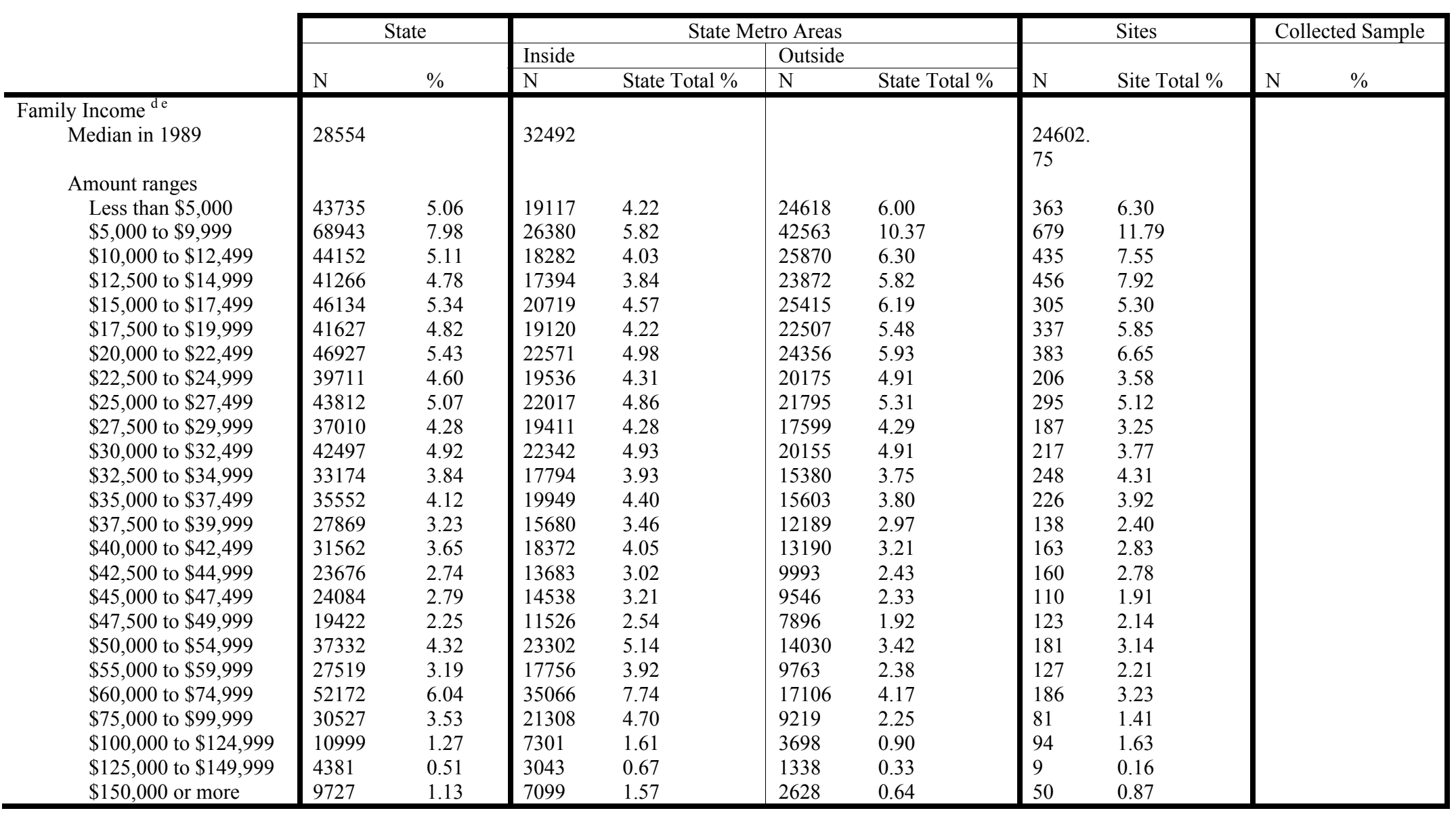


Demographics Comparison of Population Characteristics (Continued)

\begin{tabular}{|c|c|c|c|c|c|c|c|c|c|c|}
\hline & \multicolumn{2}{|c|}{ State } & \multicolumn{4}{|c|}{ State Metro Areas } & \multicolumn{2}{|r|}{ Sites } & \multicolumn{2}{|c|}{ Collected Sample } \\
\hline & \multirow[b]{2}{*}{$\mathrm{N}$} & \multirow[b]{2}{*}{$\%$} & \multicolumn{2}{|l|}{ Inside } & \multicolumn{2}{|l|}{ Outside } & \multirow[b]{2}{*}{$\mathrm{N}$} & \multirow[b]{2}{*}{ Site Total \% } & \multirow[b]{2}{*}{$\mathrm{N}$} & \multirow[b]{2}{*}{$\%$} \\
\hline & & & $\mathrm{N}$ & State Total \% & $\mathrm{N}$ & State Total \% & & & & \\
\hline Travel Time to Work ${ }^{f}$ & & & & & & & & & & \\
\hline Less than 5 minutes & 70150 & 5.10 & 24590 & 3.15 & 45560 & 7.69 & 751 & 9.94 & & \\
\hline 5 to 9 minutes & 214678 & 15.62 & 91640 & 11.72 & 123038 & 20.76 & 2370 & 31.36 & & \\
\hline 10 to 14 minutes & 239114 & 17.40 & 125940 & 16.11 & 113174 & 19.10 & 1754 & 23.21 & & \\
\hline 15 to 19 minutes & 244641 & 17.80 & 151874 & 19.43 & 92767 & 15.65 & 722 & 9.55 & & \\
\hline 20 to 24 minutes & 193484 & 14.08 & 138742 & 17.75 & 54742 & 9.24 & 437 & 5.78 & & \\
\hline 25 to 29 minutes & 66195 & 4.82 & 48890 & 6.25 & 17305 & 2.92 & 178 & 2.36 & & \\
\hline 30 to 34 minutes & 150803 & 10.97 & 99225 & 12.69 & 51578 & 8.70 & 575 & 7.61 & & \\
\hline 35 to 39 minutes & 20479 & 1.49 & 13080 & 1.67 & 7399 & 1.25 & 56 & 0.74 & & \\
\hline 40 to 44 minutes & 23257 & 1.69 & 14210 & 1.82 & 9047 & 1.53 & 51 & 0.67 & & \\
\hline 45 to 59 minutes & 58452 & 4.25 & 31792 & 4.07 & 26660 & 4.50 & 257 & 3.40 & & \\
\hline 60 to 89 minutes & 32787 & 2.39 & 13411 & 1.72 & 19376 & 3.27 & 196 & 2.59 & & \\
\hline 90 or more minutes & 19057 & 1.39 & 8526 & 1.09 & 10531 & 1.78 & 98 & 1.30 & & \\
\hline Worked at home & 41241 & 3.00 & 19733 & 2.52 & 21508 & 3.63 & 113 & 1.50 & & \\
\hline
\end{tabular}

Note: All for the State, State Metro Areas and Sites are from the the US Census Bureau 1990 Data (http://www.census.gov/main/www/cen1990.html)

${ }^{a}$ This age range was used to reflect potential sample composition based on the number of years since the 1990 Census and the desired age range on the dates that data was collected.

${ }^{\mathrm{b}}$ Number represents sample at age collected

' Percentage represents number of children within this age range and residing either inside of outside of the state's MSA's.

${ }^{\mathrm{d}}$ US Census 1990 data did not provided for finer distinctions as use din the survey.

${ }^{\mathrm{e}}$ Collected data did not include enough information to allow for computations.

${ }^{\mathrm{f}}$ This was used to establish that the potential sites were not exurbs of a US Census 1990 MSA. Sites were selected that were at least 1 hour drive time from the state's MSA's. 
APPENDIX C

Measures 


\section{Rebecca K. Summers}

127 Stonegate Circle

Morgantown, WV 26505

304-685-1672

\section{OBJECTIVE}

-To attain a full-time position which will utilize the skills of a child life specialist or related background.

\section{EDUCATION}

-Council Rock High School - Newtown, Pa

Fall 1994 to Spring 1998

-West Virginia University - Morgantown, WV

Fall 1998 to Fall 2002

-BA in Psychology (Emphasis in Pediatrics)

-Minored in Communications

-West Virginia University - Morgantown, WV

Fall 2004 to Summer 2006 -MS in Family \& Consumer Sciences (Emphasis in Child Development)

\section{EXPERIENCE}

-Research study with Dr. Lindsey Cohen in CHAMP (Child Health and Medical Procedures)

-Approved grant writing - Research with Dr. Cohen

Spring 2001

-Internship with Kaleidoscope at the SHACK

Neighborhood House - after school program (United Way)

-Volunteer for tutoring elementary students (SHACK) Spring 2002

-Assistant Pre-School teacher at

Spring 2002

SHACK - helped organize activities

-Assistant intern teacher at

West Virginia Children's Development Center

\section{SKILLS}

-Great social skills with children and people in general

-Experience in communication and group skills

-Leadership and implementing activities

-Working as a server for the past $5 \frac{1}{2}$ years at Texas Roadhouse

-Head waitress and trainer for the past 3 years

-Great experience with computers - Microsoft Office \& Windows

-Four years of French

-Type 60-70 wpm 


\section{HONORS}

-MVP on my high school soccer team. Leading scorer in Pennsylvania 1997. Played a total of 14 years.

-Captain of my Junior Varsity and Varsity soccer team.

-Competed in gymnastics for 8 years. Ranked $6^{\text {th }}$ all around in Oklahoma State Gymnastics

-Ran track for 3 years. $3^{\text {rd }}$ in SOL (Suburban One League) competition in $4 \times 4$ relays.

-Recipient of the Presidential Student Award for 200 or more hours of volunteering at West Virginia University - Fall 2002

\section{ACTIVITIES}

-Volunteering as a childlife specialist assistant at West Virginia University Ruby Memorial Children's Hospital.

-Nanny for a $2 \frac{1}{2}$ year old boy 3 days a week

-Active member of the First Baptist Church of Morgantown, WV

-Playing recreational basketball and indoor soccer at the WVU Student Recreational Center. 